\title{
Management forecasts of volatility
}

\author{
Atif Ellahie $^{1}$ (1) $\cdot$ Xiaoxia Peng $^{1}$
}

Accepted: 20 November 2020/ Published online: 5 February 2021

(C) The Author(s) 2021, corrected publication 2021

\begin{abstract}
We examine the predictive information content of the management forecasts of stock return volatility (i.e., expected volatility) that are disclosed in annual reports. We find that expected volatility predicts near-term and longer-term stock return volatility and earnings volatility incremental to implied volatility, historical volatility, firm characteristics, and alternative measures of uncertainty. We also find that expected volatility reflects managers' private information about their firms' future investment activities, such as mergers and acquisitions and R\&D intensity. Finally, we find that the predictive power of expected volatility shrinks when managers have stronger incentives to manage earnings. Overall, we provide novel evidence that management forecasts of volatility contain private information about future uncertainty that can help forecast volatility.
\end{abstract}

Keywords Volatility forecasting $\cdot$ Expected volatility $\cdot$ Disclosure $\cdot$ Management forecasts

JEL classification $\mathrm{M} 41 \cdot \mathrm{G} 13 \cdot \mathrm{G} 14$

\section{Introduction}

Forecasting stock return volatility is important for all stakeholders interested in assessing the uncertainties faced by a firm. However, developing accurate firm-level forecasts of volatility is complex and difficult, especially for outside stakeholders. Volatility forecasts typically rely on historical stock return volatility, market expectations of volatility (implied by stock option prices), or indirect assessments based on publicly available information. As insiders, managers are likely to possess private information about the firm's strategic plans and their implications for future volatility. We take advantage of accounting standards that require managers to estimate and

Atif Ellahie

atif.ellahie@eccles.utah.edu

Xiaoxia Peng

xiaoxia.peng@eccles.utah.edu

1 David Eccles School of Business, University of Utah, Salt Lake City, UT, USA 
disclose the "expected volatility" of stock returns that are used to value employee stock option awards and examine the predictive information content of these disclosures. ${ }^{1}$ If managers incorporate their private information into their estimates of expected volatility, this may result in superior volatility forecasting. If, however, managers have strong incentives to bias expected volatility to manage earnings, then their forecasting power may be reduced. We are the first researchers to consider expected volatility as a volatility forecast directly provided by managers and examine the incremental value of this forecast in predicting stock return volatility. We also illuminate the nature of managers' private information that may be incorporated in expected volatility and assess whether the informativeness of expected volatility is undermined when managers have incentives to manage earnings.

We argue that managers' expected volatility (hereafter EVOL) surpasses other volatility forecasts because it incorporates managers' private information. Managers' investing, financing, and production decisions affect current and future firm performance, including the firm's earnings growth, profitability, and earnings volatility. Also, managers are well positioned to interpret the future effects of past and current corporate events, such as mergers and acquisitions, and marketwide events, such as business combinations by competitors. ${ }^{2}$ If managers estimate $E V O L$ in a manner that is internally consistent with their information, then $E V O L$ should reflect their knowledge of the implications for future firm performance of these decisions and events. This private information distinguishes $E V O L$ from volatility forecasts that rely solely on public information, such as historical stock returns, firm fundamentals, information about the industry and macroeconomic environment, and option prices (for firms with traded options).

Managers' information advantage notwithstanding, biases and errors could still reduce the informativeness of $E V O L$. Research suggests that managers may strategically bias $E V O L$ downward to manipulate earnings upward or to reduce the perceived compensation of corporate executives (e.g., Aboody et al. 2006; Hodder et al. 2006; Johnston 2006; Choudhary 2011). ${ }^{3}$ Alternatively, managers may strategically bias EVOL upward to deflate earnings to lower strike prices and increase their eventual gains from stock option awards. These earnings management incentives could bias $E V O L$ and reduce its forecasting power. The informativeness of $E V O L$ could also be affected by difficulties in forecasting or the proprietary costs of disclosing private information about future investments and cost of capital.

In this paper, we examine the informativeness of $E V O L$ for forecasting stock return volatility (i.e., standard deviation of future stock returns). We first provide large sample evidence that higher $E V O L$ predicts higher stock return volatility over the near term

\footnotetext{
${ }^{1}$ SFAS 123 from 1996 to 2006, and SFAS 123R (currently known as ASC 718) since 2006 (Financial Accounting Standards Board (FASB) 1995, 2004).

2 The Securities and Exchange Commission provides implementation guidelines for this disclosure: "The staff believes that Company B should consider those future events that it reasonably concludes a marketplace participant would also consider in making the estimation. For example, if Company B has recently announced a merger with a company that would change its business risk in the future, then it should consider the impact of the merger in estimating the expected volatility if it reasonably believes a marketplace participant would also consider this event" (see SEC Staff Accounting Bulletin Topic 14).

${ }^{3}$ Higher expected volatility increases the estimated value of granted employee stock options, which increases equity-based compensation expense and the perceived total executive compensation.
} 
(i.e., next year). This forecasting power is incremental to that of a model with implied volatility, historical volatility, firm characteristics, industry fixed effects, and year fixed effects. Further, our inferences are unchanged if we control for firm fixed effects, instead of industry fixed effects. Importantly, in out-of-sample forecast accuracy tests, we find that adding $E V O L$ to the forecasting model reduces forecast errors for one-yearahead stock return volatility in $76 \%-88 \%$ of cases, with the reductions averaging $0.37 \%-0.49 \%$, depending on the forecasting model. We also find that EVOL has predictive power over longer horizons (i.e., two, three, and four years ahead). Further, the estimated coefficient on $E V O L$ declines as we control for realizations of stock return volatility. Taken together, these results are consistent with EVOL capturing forwardlooking information over both the near and long term.

After establishing the forecasting power of $E V O L$ for stock return volatility, we attempt to identify the information channel through which $E V O L$ improves forecasts. To do this, we examine the forecasting power of $E V O L$ for two underlying drivers of stock return volatility: earnings volatility and investment decisions. We find that $E V O L$ has predictive power for both. First, we show that firms with higher $E V O L$ have higher standard deviation of future earnings and, on average, are more likely to experience extreme realizations of future earnings growth. This suggests that EVOL incorporates private information about earnings volatility and can be used to identify firms with more volatile earnings generation. Turning to current and future investments, we find that firms with higher EVOL are more likely to engage in mergers and acquisitions (M\&A) and to have higher R\&D intensity in future periods, conditional on current levels of M\&A and R\&D intensity. These results are consistent with EVOL reflecting the implications of investments with uncertain outcomes and support our conjecture that EVOL contains managers' private information about future strategic plans.

Next, we explore the effect of earnings management incentives on the informativeness of EVOL. To capture variation in the managerial incentives to manipulate earnings, we examine five proxies for earnings management incentives: adoption of SFAS 123R, level of employee stock option grants, incentives to avoid losses, proximity to a target earnings level, and strength of corporate governance (Burgstahler and Dichev 1997; Degeorge et al. 1999; Aboody et al. 2006; McAnally et al. 2008). To the extent that these proxies capture incentives to bias $E V O L$, we expect the forecasting power of $E V O L$ to decline in their presence. Consistent with our expectation, in within-firm analyses, we find that the predictive power of $E V O L$ for stock return volatility is significantly attenuated when earnings management incentives are higher.

Our main specification, which includes implied volatility, historical volatility, firm characteristics, industry fixed effects, and year fixed effects, shows that EVOL has incremental information content. We also examine the robustness of our inferences to including alternative market-based, accounting-based, and disclosure-based measures of uncertainty for constrained subsamples: (1) dispersion in analyst forecasts for earnings per share (EPS) from I/B/E/S; (2) accounting characteristics following Sridharan (2015); (3) dispersion in quantile-based forecasts of return on net operating assets (RNOA) following Correia et al. (2018); (4) risk factor disclosures following Campbell et al. (2014); and (5) analyst risk ratings from Lui et al. (2007). We find that the information content of $E V O L$ for future stock return volatility is incremental to that of these measures. Our results are also robust to several alternative specifications, such as a change specification and Fama-MacBeth estimations. 
Finally, to assess the extent to which the incremental information in $E V O L$ is incorporated into option prices, we examine whether $E V O L$ explains returns to a volatility straddle (i.e., a long position in both an at-the-money call and put option of equivalent maturity). Research has used volatility straddle returns to assess the pricing of information by the options market (Goyal and Saretto 2009; Goodman et al. 2018). We find that the deviations of EVOL from implied volatility are positively associated with volatility straddle returns, even after transaction costs, suggesting that option prices do not fully incorporate the information in EVOL.

Our paper contributes to several streams of literature. First, it extends the literature on volatility forecasting. Research in this area has focused on developing volatility prediction models based on realized volatility and stochastic volatility models (e.g., Andersen et al. 2003; Andersen et al. 2005; Andersen et al. 2006; Corsi 2009; see Poon and Granger 2003 and Poon and Granger 2005 for literature reviews). We show that managers' stock return volatility forecasts disclosed in financial reports $(E V O L)$ have predictive power that is incremental to that of implied volatility, historical volatility, and firm characteristics. Further, we provide novel evidence that these forecasts have an information advantage, because they contain otherwise-unavailable private information about strategic decisions.

Second, our paper contributes to prior findings that executives might have incentives to manage earnings upward by opportunistically selecting employee stock option valuation parameters, including expected volatility (e.g., Aboody et al. 2006; Bartov et al. 2007; Choudhary 2011). In work on earnings management incentives and employee stock options, researchers have used deviations from selected benchmarks to capture biases in EVOL. Our approach assumes nothing about the correct benchmark and instead evaluates the predictive power of $E V O L$ for stock return volatility. We find that the incremental predictive power of $E V O L$ for stock return volatility is significantly lower when earnings management incentives are stronger. This is consistent with these incentives leading to biases that reduce the information content of EVOL.

Third, our paper contributes to research that incorporates accounting information, firm risk disclosures, or third-party analysts' risk assessments to assess firm risk and uncertainty (e.g., Lui et al. 2007; Kravet and Muslu 2013; Campbell et al. 2014; Chang et al. 2020; Sridharan 2015; Konstantinidi and Pope 2016; Correia et al. 2018; Goodman et al. 2018). We extend these studies by providing evidence on the predictive power of a forecast of stock return volatility directly provided by managers $(E V O L)$. Our approach differs from prior studies in that it neither requires additional processing of accounting information or risk disclosures nor relies on subjective third-party assessments of risk.

Finally, our paper contributes to the broader literature that uses firm disclosures and macroeconomic information to improve forecasts of firm fundamentals (e.g., Ou and Penman 1989a, b; Kothari 2001; Dhaliwal et al. 2013; Li et al. 2014). For example, Minton et al. (2002) find that adding historical volatility of cash flows and earnings to the forecasting model can improve forecasts of the levels of cash flows and earnings. We show that management forecasts of volatility predict earnings volatility incremental to historical earnings volatility.

\section{Empirical methodology}

Since 1996, managers have been required to disclose their expectations of stock return volatility $(E V O L)$ for use in an option pricing model that estimates the grant date fair 
value of employee stock options awarded during the year. We take advantage of this disclosure to assess the cross-sectional predictive information content of EVOL for near-term and long-term stock return volatility. To assess the information channel that underlies this predictive ability, we then examine whether EVOL captures managers' private information about the effects of ongoing strategic decisions on future firm fundamentals. Finally, we examine the effect of managerial incentives to manipulate earnings on the informativeness of $E V O L$ for future stock return volatility.

\subsection{Research design}

First, using firm-level cross-sectional regressions, we examine whether EVOL that is estimated at the end of each fiscal year can predict stock return volatility over the near term (i.e., the next year). If $E V O L$ helps to forecast future realizations, we expect firms with higher $E V O L$ to have higher future stock return volatility. Specifically, we estimate the following empirical model using firm-year observations (firm subscripts suppressed).

$$
\text { Volatility }_{t+1}=\gamma_{0}+\gamma_{1} \text { EVOL }_{t}+\gamma_{2} \text { IVOL }_{t}+\gamma_{3} \text { HVOL }_{t}+\Sigma \gamma X_{t}+\varepsilon_{t+1} \text {. }
$$

In Eq. (1), the dependent variable is the natural logarithm of future stock return volatility over the next fiscal year. The coefficient $\gamma_{1}$ is the variable of interest, and EVOL is the expected stock return volatility over the life of the options granted during the fiscal year and is disclosed in the stock compensation expense footnote in the firm's 10-K. Since EVOL could reflect managers' expectations about stock return volatility beyond the next year, we also examine future stock return volatility over the longer term (i.e., the next two to four years). ${ }^{4}$ The start month for the future stock return volatility calculation is based on the fiscal year-end, because the information set used by managers to estimate $E V O L$ extends to then. ${ }^{5}$

To assess the incremental information content of EVOL, we control for common sources of volatility information. The implementation guidance for the managers' disclosure gives firms discretion to use different information sources to estimate expected volatility; these sources include implied volatility, historical volatility, and other volatility-related current and future events. ${ }^{6}$ Thus we control for implied volatility $(I V O L)$ for the subset of firms with available option pricing data. ${ }^{7}$

\footnotetext{
${ }^{4}$ While our focus is on forecasting horizons of one year and beyond, we also study, in robustness tests, stock return volatility over horizons of one, three, and six months.

${ }^{5}$ In robustness tests, we also measure future stock return volatility starting at the $10-\mathrm{K}$ filing date.

${ }^{6}$ To better understand how firms might combine these different information sources, we read disclosures by a subsample of 200 firms that mention "implied volatility" or "implied volatilities" in their 10-K. Consistent with the discretion allowed by the standard, we find that firms are relatively opaque about the methodology used to estimate expected volatility. We find that eight of the 200 firms do not disclose any information about the methodology. Of the remaining 192 firms, 10\% disclose that they use only historical volatility, 15\% disclose that they use only implied volatility, $65 \%$ disclose that they use a combination of historical volatility and implied volatility, and $10 \%$ disclose that they use peer information.

${ }^{7}$ We collect implied volatility from the standardized option price files (stdopdYYYY) in OptionMetrics for 30-day call options. We choose the 30-day option maturity to collect $I V O L$ since data coverage for longerdated options declines drastically and since this is the most liquid and best populated maturity in OptionMetrics. Further, using a constant maturity enables cross-sectional comparisons. However, a potential limitation of using implied volatility from 30-day options is that it captures short-horizon expectations for volatility and its forecasting ability may decline over longer horizons. In robustness tests, we use IVOL based on 360-day and 720-day options, which are available for fewer firms.
} 
We also control for historical stock return volatility, measured as the standard deviation of stock returns over the four years prior to fiscal year-end (HVOL). We select the four-year timeframe for several reasons. First, we want a duration that is appropriate for measuring historical volatility — one that balances increased information from adding more time-series data against the cost of constraining the sample. Second, the implementation guidance for this disclosure suggests that firms use historical information over a period commensurate with the expected term of the employee stock option, while considering the possible early exercise of options by employees. We find that the mean and median expected term of granted options for our sample is five years with a standard deviation of 2.2 years. The 25 th and 75 th percentiles of the expected term are four years and six years, respectively. We also find that from 1996 through 2015, the mean expected term declines from approximately 5.6 years to 4.6 years. Further, Huddart and Lang (1996) and Hemmer et al. (1996) find that employees tend to exercise options before their expiration date, which suggests that we should use less than five years of historical data. Therefore we measure historical volatility over the previous four years in our models. ${ }^{8}$

Finally, we control for $X_{t}$, a vector of variables that are expected to relate to stock return volatility. The variables - historical earnings volatility over the previous four years, size, book-to-price, earnings-to-price, an earnings loss indicator, leverage, return on assets, market beta, and momentum - have been used in the literature on risk and returns (e.g., Fama and French 1992, 1995; Lyle et al. 2013; Lewellen 2015; Penman et al. 2018; Ellahie et al. 2020; Ellahie 2020). All are described in Appendix 1.

To examine the cross-sectional predictive power of EVOL for future stock return volatility, we use pooled regressions with industry and year fixed effects and estimate Eq. (1). ${ }^{9}$ The inclusion of industry fixed effects controls for between-industry variation. Volatility could also vary over time, due to fluctuations in the macroeconomic environment, so we use year fixed effects to control for firm-invariant time effects. Since $E V O L$ is a firm-specific characteristic, controlling for industry and year fixed effects allows us to focus on cross-sectional variation at the firm level. Had we controlled for firm fixed effects instead, we would have been left with only within-firm variation, effectively removing the cross-sectional variation we want to examine. Nonetheless, we do also estimate and report specifications with firm fixed effects.

We argue that expected volatility $(E V O L)$ has incremental predictive power for stock return volatility, because it incorporates managers' private information. This information pertains to strategic decisions about investing, financing, and production and reflects uncertainties that can affect both expected volatility and variability in future performance. To the extent that managers incorporate their private information about these strategic decisions into expected volatility, EVOL should also predict earnings volatility. Thus we use the following model to test whether higher EVOL predicts higher future volatility in return on assets, as a measure of earnings volatility.

$$
\sigma(R O A)_{t+2}=\gamma_{0}+\gamma_{1} E_{V O L}+\gamma_{2} I V O L_{t}+\gamma_{3} H V O L_{t}+\Sigma \gamma X_{t}+\varepsilon_{t+1}
$$

\footnotetext{
${ }^{8}$ In robustness tests, instead of measuring standard deviation of stock returns over the prior four years, we control for of individual lags of annual stock return volatility.

${ }^{9}$ In robustness tests, we also use Fama and Macbeth (1973) annual cross-sectional regressions with industry fixed effects.
} 
In Eq. (2), $\sigma(R O A)_{t+2}$ is future earnings volatility estimated using quarterly return on assets over the next two years. We use a two-year-ahead horizon, so that we have at least eight quarters of data to estimate earnings volatility, which helps to reduce estimation errors. As in Eq. (1), we control for implied volatility, historical stock return volatility, historical earnings volatility, firm characteristics, industry fixed effects, and year fixed effects. We also estimate a model with firm fixed effects.

In a similar model, we also examine extreme realizations of future earnings growth two years ahead (i.e., from $t+1$ to $t+2$ ) as another way to capture volatile future earnings. If high $E V O L$ captures more volatile earnings generation, examining extremely high or low future earnings growth is another way to test for this. Specifically, we estimate the following logistic regressions (firm subscript suppressed).

$$
\text { Low } / \text { High } \text { Growth }_{t+2}=\gamma_{0}+\gamma_{1} \text { EVOL }_{t}+\gamma_{2} \text { IVOL }_{t}+\gamma_{3} \text { HVOL }_{t}+\Sigma \gamma X_{t}+\varepsilon_{t+1} \text {. }
$$

We estimate Eq. (3) for future Low Growth and High Growth separately. Low Growth is an indicator variable that takes the value of 1 when the yearly earnings growth from time $t+1$ to time $t+2$ is in the lowest quintile and 0 otherwise. High Growth is an indicator variable that takes the value of 1 when the yearly earnings growth from time $t+1$ to time $t+2$ is in the highest quintile and 0 otherwise. When the dependent variable is Low Growth (High Growth), we remove the highest (lowest) quintile of yearly earnings growth, so the baseline is always the middle three quintiles.

Next, using the same model as in Eq. (2), we test whether future investment decisions over the next two years are associated with $E V O L$. If managers expect to invest with uncertain payoffs, EVOL may reflect those expectations. Therefore we expect investments with uncertain outcomes, such as mergers and acquisitions $(M \& A)$ and research and development $(R \& D)$, to be positively associated with $E V O L$.

Finally, we examine whether incentives for managers to manipulate earnings undermine the informativeness of $E V O L$ for future stock return volatility. Research argues that managers may strategically bias $E V O L$ downward to manipulate earnings upward or to reduce perceived compensation to corporate executives (e.g., Aboody et al. 2006; Hodder et al. 2006; Johnston 2006; Choudhary 2011). Managers may also deflate earnings to lower strike prices and increase their eventual gains from stock option awards. Based on this research, we expect stronger earnings management incentives to introduce biases that weaken the predictive information content of EVOL. To test this conjecture, we estimate the following empirical model using firm-year observations (firm subscripts suppressed).

$$
\begin{aligned}
\text { Volatility }_{t+k}= & \gamma_{0}+\gamma_{1} \text { EVOL }_{t}+\gamma_{2} E_{t}+\gamma_{3} E_{V O L} \times E M_{t}+\gamma_{4} I V O L_{t} \\
& +\gamma_{5} \text { HVOL }_{t}+\Sigma \gamma X_{t}+\varepsilon_{t+1} .
\end{aligned}
$$

In Eq. (4), we follow the literature (Burgstahler and Dichev 1997; Degeorge et al. 1999; Aboody et al. 2006; McAnally et al. 2008) and use several proxies to capture variation in managerial incentives to manipulate earnings $\left(E M_{t}\right)$ : (1) adoption of SFAS 123R (Post 123R), (2) level of employee stock option grants (Option Grants), (3) incentives to avoid losses (Small Profit), (4) proximity to a target earnings level (Small Miss or Small Beat), and (5) strength of corporate governance ( $G$-Index). The dependent variable is the natural 
logarithm of stock return volatility over the next one or two years. We control for implied volatility, historical stock return volatility, historical earnings volatility, firm characteristics, and year fixed effects. Further, to better isolate the effect of managerial incentives on the informativeness of $E V O L$, we account for the effects of unobservable firm characteristics by controlling for firm fixed effects. Our coefficient of interest is $\gamma_{3}$. We expect a negative and significant coefficient on this interaction term.

\subsection{Sample description}

Our sample starts with 78,350 firm-years with nonmissing Compustat and CRSP data over the period from 1996 to 2017. We use a Python algorithm to collect expected volatility from the Employee Stock Option Compensation Expense footnote in each firm's Form 10-K annual report filed with the Securities and Exchange Commission (SEC) and supplement this with Compustat data available since $2005 .^{10}$

Our algorithm searches for the firm's option pricing model for employee stock options (e.g., Black-Scholes, binomial, or Monte Carlo) and then captures the expected volatility that appears in the footnote in the $10-\mathrm{K}$ filing. ${ }^{11} \mathrm{We}$ verify our algorithm's accuracy in capturing EVOL against a random set of hand-collected data and find that the algorithm performs well. However, as with all procedures for programmatic data collection from unstructured sources, there is a margin for error. Therefore we also trim the top and bottom $0.1 \%$ to reduce the influence of potential outliers due to data errors. ${ }^{12}$

Table 1, Panel A, describes sample selection. We require nonmissing historical and future stock return volatility as well as nonmissing expected volatility, which results in a primary sample of 39,641 firm-years over the 1996 to 2015 period. Our sample ends in 2015, as we require two-year-ahead realizations for our main dependent variables. For firms with nonmissing historical and future stock return volatility, our sample covers approximately $60 \%$ of all firm-years in the Compustat-CRSP merged universe.

Table 1 also reports the by-year (Panel B) and by-industry (Panel C) distribution for our sample. We observe a decline in observations after 2006, consistent with an overall declining trend in the use of employee stock options over recent periods (Carter et al. 2007; Hayes et al. 2012). Our sample is not overly concentrated in any individual industry; it generally reflects the industry composition of the CRSP-Compustat merged universe that we started with (see right-most column of Panel C). Financial services, the most heavily represented industry, accounts for $20.0 \%$ of the observations, followed by business equipment with $18.6 \%$.

\footnotetext{
${ }^{10}$ Based on overlapping observations, expected volatility collected using our algorithm has a Pearson (Spearman) correlation of 0.92 (0.94) with the Compustat variable (optvol), which underscores the quality of our data.

${ }^{11}$ Firms can disclose expected volatility used to calculate stock compensation expense in the annual report $(10-\mathrm{K})$ or in the annual proxy statement (DEF 14A) (Cadman et al. 2020). Disclosure in either the 10-K or the proxy statement may be incorporated by reference in the other filing. In our primary analysis, we focus on disclosure in 10-Ks only, because (1) 10-Ks are the main venue for this disclosure, and (2) the proxy statement only includes stock options granted to named executive officers and directors, while the 10-K covers broadbased employee stock option plans. Nevertheless, in robustness tests we use EVOL disclosed in proxy statements. We find that our sample increases by approximately $5 \%$, and our main results are unchanged. We have also restricted our main analyses to using only Compustat data for EVOL and find similar results.

${ }^{12}$ For approximately 2000 firm-year observations with extreme values of $E V O L$, we manually verify the data. In robustness tests, we have also trimmed at the top and bottom $1 \%$ level and find consistent results.
} 
Table 1 Sample

Panel A: Sample Selection

Nonmissing Compustat and CRSP data for firm characteristics (1996-2017)

Firm-years

Exclude observations with missing historical or future return volatilities

78,350

Exclude observations with missing expected volatility assumptions

$-27,100$

Primary sample (1996-2015)

39,641

Primary sample when requiring implied volatility (1996-2015)

22,815

\begin{tabular}{|c|c|c|c|c|c|c|}
\hline \multicolumn{3}{|c|}{ Panel B: By Year Breakdown } & \multicolumn{2}{|c|}{ Panel C: By Industry Breakdown } & \multirow[b]{2}{*}{ Freq \% } & \multirow[b]{2}{*}{$\begin{array}{l}\text { Freq \% in } \\
\text { CRSP-Compustat } \\
\text { Merged Universe }\end{array}$} \\
\hline Year & Firm-years & Freq \% & Industry & Firm-years & & \\
\hline 1996 & 696 & 1.8 & Business Equipment & 7,374 & 18.6 & 16.5 \\
\hline 1997 & 1,146 & 2.9 & Chemicals & 970 & 2.5 & 2.2 \\
\hline 1998 & 1,195 & 3.0 & Durable Goods & 790 & 2.0 & 2.1 \\
\hline 1999 & 1,229 & 3.1 & Energy & 1,285 & 3.2 & 3.8 \\
\hline 2000 & 1,304 & 3.3 & Health & 4,451 & 11.2 & 9.8 \\
\hline 2001 & 1,425 & 3.6 & Manufacturing & 3,790 & 9.6 & 9.6 \\
\hline 2002 & 2,104 & 5.3 & Financial Services & 7,918 & 20.0 & 22.6 \\
\hline 2003 & 2,188 & 5.5 & Nondurable Goods & 1,975 & 5.0 & 5.1 \\
\hline 2004 & 3,137 & 7.9 & Other & 5,018 & 12.7 & 12.4 \\
\hline 2005 & 3,094 & 7.8 & Retail & 4,155 & 10.5 & 10.5 \\
\hline 2006 & 2,794 & 7.1 & Telecommunications & 1,008 & 2.5 & 2.3 \\
\hline 2007 & 2,574 & 6.5 & Utilities & 907 & 2.3 & 3.2 \\
\hline 2008 & 2,480 & 6.3 & & & & \\
\hline 2009 & 2,381 & 6.0 & & & & \\
\hline 2010 & 2,325 & 5.9 & & & & \\
\hline 2011 & 2,259 & 5.7 & & & & \\
\hline 2012 & 2,099 & 5.3 & & & & \\
\hline 2013 & 1,988 & 5.0 & & & & \\
\hline 2014 & 1,831 & 4.6 & & & & \\
\hline 2015 & 1,392 & 3.5 & & & & \\
\hline
\end{tabular}

Table 2 reports the descriptive statistics for our main variables. The historical stock return volatilities are consistent with those in previous studies. For example, we report mean volatilities of 0.44 for Volatility $t_{t}$ and 0.49 for $H V O L_{t}$. In comparison, the mean monthly realized volatility $\left(\operatorname{StdDev}_{-1,-12}\right)$ reported in Table 2 of Lewellen (2015) is 0.15 for "all stocks," which is equivalent to annualized realized volatility of 0.52 . Further, the distributions of the control variables we use (e.g., Size, Book-to-price, Earnings-toprice, Beta, Leverage, Momentum) resemble those in prior studies (Lewellen 2015; Penman et al. 2018). For example, our mean Book-to-price of 0.63 resembles the 0.62 in Table 1 of Penman et al. (2018), and our median Earnings-to-price of 0.041 resembles 
Table 2 Descriptive Statistics

\begin{tabular}{|c|c|c|c|c|c|c|}
\hline & Obs. & Mean & Std. Dev. & 25 th & Median & 75 th \\
\hline \multicolumn{7}{|l|}{ Main Variables: } \\
\hline Volatility $_{t+1}$ & 39,641 & 0.438 & 0.306 & 0.241 & 0.359 & 0.540 \\
\hline$E V O L_{t}$ & 39,641 & 0.494 & 0.255 & 0.310 & 0.440 & 0.620 \\
\hline$I V O L_{t}$ & 22,815 & 0.461 & 0.252 & 0.286 & 0.394 & 0.565 \\
\hline$H V O L_{t}$ & 39,641 & 0.487 & 0.280 & 0.288 & 0.419 & 0.611 \\
\hline$\sigma(R O A)_{t}$ & 39,641 & 0.060 & 0.116 & 0.010 & 0.024 & 0.063 \\
\hline Size $_{t}$ & 39,641 & 6.205 & 2.073 & 4.698 & 6.154 & 7.621 \\
\hline Book-to-price $_{t}$ & 39,641 & 0.626 & 0.771 & 0.290 & 0.504 & 0.808 \\
\hline Earnings-to-price $_{t}$ & 39,641 & -0.057 & 0.721 & -0.015 & 0.041 & 0.067 \\
\hline Loss Indicator $_{t}$ & 39,641 & 0.280 & 0.449 & 0.000 & 0.000 & 1.000 \\
\hline Leverage $_{t}$ & 39,641 & 0.413 & 0.276 & 0.177 & 0.361 & 0.621 \\
\hline$R O A_{t}$ & 39,641 & -0.023 & 0.248 & -0.010 & 0.024 & 0.066 \\
\hline Beta $_{t}$ & 39,641 & 1.203 & 0.920 & 0.580 & 1.062 & 1.643 \\
\hline Momentum $_{t}$ & 39,641 & 0.137 & 0.600 & -0.172 & 0.066 & 0.314 \\
\hline \multicolumn{7}{|l|}{ Additional Variables: } \\
\hline Volatility $_{t+2}$ & 35,382 & 0.433 & 0.321 & 0.237 & 0.352 & 0.531 \\
\hline Volatility $_{t+3}$ & 31,209 & 0.427 & 0.314 & 0.235 & 0.346 & 0.522 \\
\hline Volatility $_{t+4}$ & 27,415 & 0.421 & 0.309 & 0.233 & 0.342 & 0.515 \\
\hline$\sigma(R O A)_{t+2}$ & 33,727 & 0.042 & 0.063 & 0.008 & 0.018 & 0.045 \\
\hline$M \& A_{t+1}$ & 38,924 & 0.033 & 0.178 & 0.000 & 0.000 & 0.000 \\
\hline$M \& A_{t+2}$ & 38,924 & 0.058 & 0.233 & 0.000 & 0.000 & 0.000 \\
\hline$R \& D_{t+1}$ & 20,919 & 0.081 & 0.118 & 0.004 & 0.035 & 0.107 \\
\hline$R \& D_{t+2}$ & 20,919 & 0.148 & 0.209 & 0.008 & 0.066 & 0.202 \\
\hline$C V(\text { Analyst Estimates })_{t}$ & 26,678 & 0.167 & 0.379 & 0.022 & 0.050 & 0.143 \\
\hline$\sigma(E / P)_{t}$ & 38,608 & 0.133 & 0.458 & 0.013 & 0.029 & 0.086 \\
\hline$\sigma(\Delta B / P)_{t}$ & 38,608 & 0.325 & 0.530 & 0.089 & 0.173 & 0.348 \\
\hline$\sigma(R N O A \text { quantile })_{t}$ & 35,239 & 0.323 & 0.317 & 0.093 & 0.224 & 0.364 \\
\hline Risk Factors $_{t}$ & 20,173 & 7.480 & 0.943 & 7.128 & 7.625 & 8.027 \\
\hline
\end{tabular}

This table reports descriptive statistics for the variables used in our analyses. All variables have been trimmed at the top and bottom $0.1 \%$ level each year. See Appendix 1 for a detailed description of the variables

the 0.047 in Table 1 of Penman et al. (2018). The distributions of Momentum and Beta are also generally consistent with those in Table 2 of Lewellen (2015).

We also plot cross-sectional averages of EVOL, IVOL, and HVOL by year from 1996 to 2015 (see Fig. 1). Panel A of Fig. 1 shows the average volatilities over time. The volatilities tend to be higher during recessions (i.e., 2001 and 2007-2009). We also observe that the relative magnitudes of the three measures of volatility are time-varying. For example, in the 1996-2004 (1996-2002) period, expected volatility is lower than historical volatility (implied volatility).

Panel B of Fig. 1 reports deviations of EVOL from IVOL and HVOL. The difference between $E V O L$ and $I V O L$ ranges from -0.49 to +0.35 , and the difference between $E V O L$ and $H V O L$ ranges from -0.37 to +0.32 . Further, EVOL is within $5 \%$ of $H V O L$ 
a Yearly Average Volatility

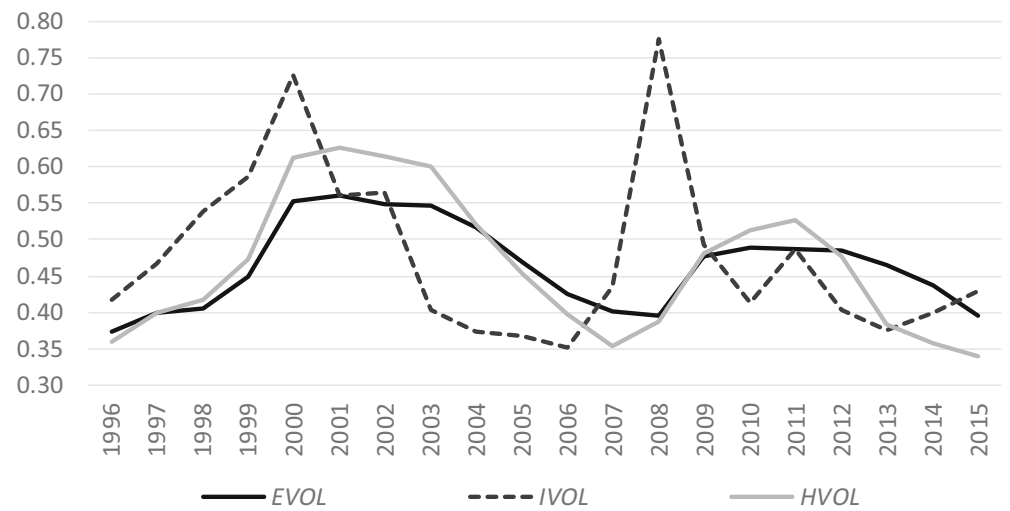

b Deviations of EVOL from IVOL and $H V O L$

\begin{tabular}{ccc} 
Rank of Difference & $E V O L-I V O L$ & $E V O L-H V O L$ \\
\hline 1 & -0.49 & -0.37 \\
2 & -0.18 & -0.12 \\
3 & -0.08 & -0.06 \\
4 & -0.03 & -0.02 \\
5 & 0.01 & 0.00 \\
6 & 0.05 & 0.03 \\
7 & 0.08 & 0.05 \\
8 & 0.12 & 0.09 \\
9 & 0.18 & 0.14 \\
10 & 0.35 & 0.32 \\
\hline
\end{tabular}

Fig. 1 Yearly Average Volatility and Deviations of $E V O L$ from $I V O L$ and $H V O L$. This figure plots the average volatilities by industry and year over the 1996-2015 period. Panel a plots the average expected volatility $(E V O L)$, implied volatility $(I V O L)$, and historical volatility $(H V O L)$ for each year over the sample period. Panel b reports the average differences between EVOL, IVOL, and HVOL for each quintile rank. All variables are defined in Appendix 1

(IVOL) only $15.7 \%(10.0 \%)$ of the time in our entire sample. This suggests that EVOL is unlikely to be simply based on historical or implied volatility or both and may contain incremental information.

Table 3 reports the time-series average of cross-sectional correlations between the main variables. The natural logarithm of future stock return volatility is positively correlated with $E V O L_{t}$, implied volatility, and historical volatilities. For example, Volatility $y_{t+1}$ and $E V O L_{t}$ have a Pearson correlation coefficient of 0.55 and a Spearman correlation coefficient of 0.61. Volatilities are generally negatively correlated with Size, Earnings-to-price, Leverage, and $R O A$ and are generally positively correlated with Earnings Volatility and Beta.

\section{Results}

\subsection{Forecasting stock return volatility using $E V O L$}

We first examine the predictive information content of $E V O L$ for the natural logarithm of one-year-ahead stock return volatility in Table 4. In a model with EVOL by itself in column 


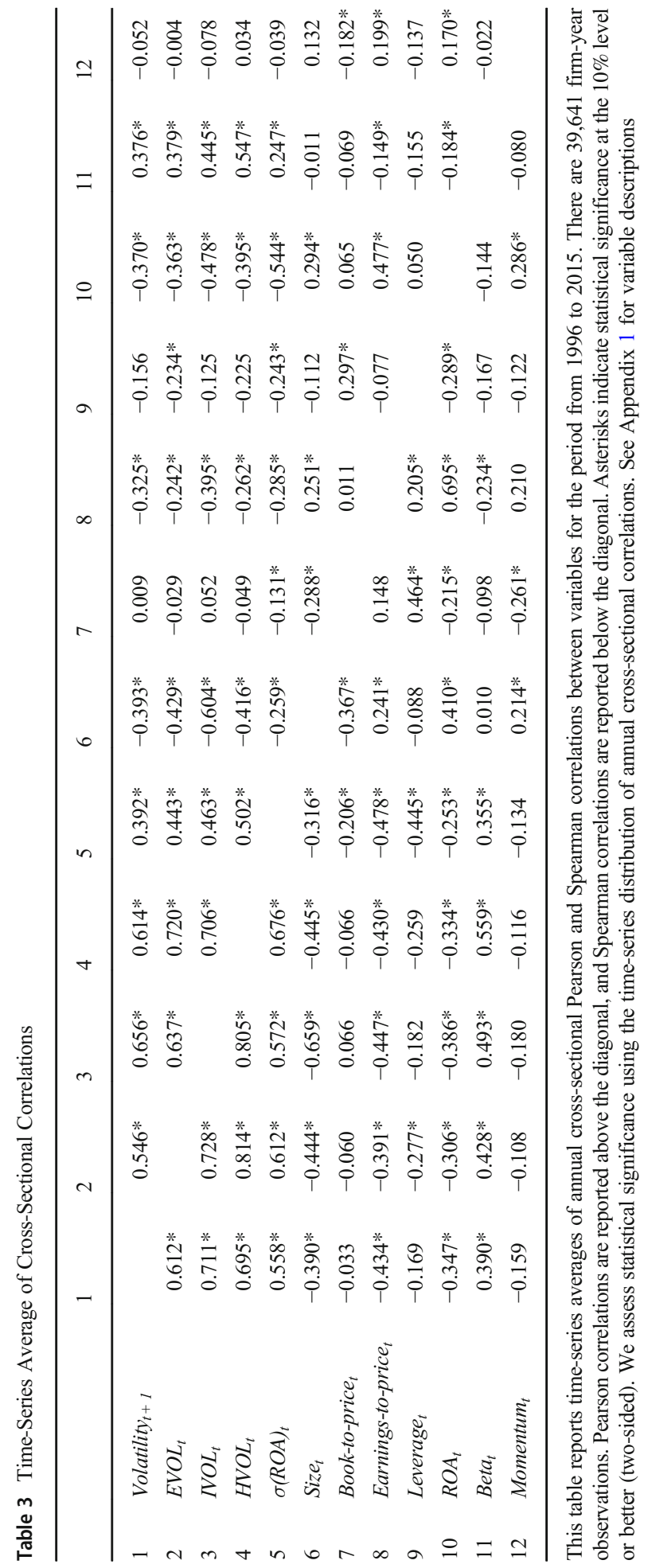


1, we find that $E V O L$ is positively and significantly associated with future stock return volatility and explains $23.0 \%$ of the variation in volatility. In column 2 , we include historical stock return volatility $(H V O L)$ as well as industry and year fixed effects and find that $E V O L$ forecasts stock return volatility incremental to historical volatility. Also, consistent with managers using historical volatility, industry information, and year information as inputs to estimate $E V O L$, we find that the coefficient on $E V O L$ declines from 1.117 to 0.401 . In column 3, we control for firm characteristics that we expect to relate to future volatility. We find that the coefficient on EVOL remains positive and significant at 0.231 , and the model has an adjusted $\mathrm{R}^{2}$ of $56.3 \%$. In column 4 , we control for implied volatility (IVOL), which reduces our sample from 39,641 to 22,815 , due to option data requirements. We find that $E V O L$ continues to have incremental explanatory power for one-year-ahead stock return volatility. The coefficient on $E V O L$ is positive and significant at 0.244 , and the adjusted $\mathrm{R}^{2}$ is $60.8 \%$, suggesting that $E V O L$ has between-firm predictive power for future volatility that is incremental to implied volatility, historical volatility, firm characteristics, industry fixed effects, and year fixed effects. ${ }^{13}$ Finally, although we are interested primarily in examining cross-sectional variations, we replace industry fixed effects with firm fixed effects in column 5. The coefficient on $E V O L$ remains positive and significant, suggesting that $E V O L$ also has within-firm predictive power for future volatility.

Next, we examine the out-of-sample forecast accuracy of EVOL for the natural logarithm of future stock return volatility and report the results in Fig. 2. We compare the out-of-sample absolute forecast errors between a model that includes EVOL and a model that excludes EVOL. First, we randomly select 15 of the 20 years from our sample to estimate the coefficients from a baseline forecasting model, use the estimated coefficients to predict stock return volatility for the remaining five hold-out years, and then calculate absolute forecast errors as the absolute difference between predicted and realized one-year-ahead stock return volatility. Second, we add EVOL to the baseline forecasting model, re-estimate the coefficients in the same estimation sample, and estimate predicted values and absolute forecast errors for the same remaining holdout sample. We store the mean percentage change in absolute forecast errors for the hold-out sample after including $E V O L$ in the forecasting model.

We repeat this process 1000 times to generate a distribution of percentage change in absolute forecast errors and plot this distribution to evaluate the incremental performance of a forecasting model that includes $E V O L$. The baseline forecasting model in Panel A (Panel B) is the model in Table 4 column 3 (column 4) but without EVOL. Adding EVOL to the baseline model reduces absolute forecast errors in $88.4 \%(75.9 \%)$ of the 1000 out-of-sample forecasting simulations in Panel A (Panel B), with the average reduction being $0.49 \%(0.37 \%)$. Thus $E V O L$ has out-of-sample forecasting power incremental to that of implied volatility, historical volatility, firm characteristics, industry fixed effects, and year fixed effects.

Until now, we have focused on the incremental predictive power of EVOL for one-yearahead stock return volatility. However, many strategic decisions have long-term consequences, and $E V O L$ is supposed to forecast volatility over the expected term of the employee stock option (mean and median of five years in our sample). This suggests that EVOL may

\footnotetext{
${ }^{13}$ In robustness tests, we also use Fama-Macbeth regressions with industry fixed effects. We find that the estimated coefficients from pooled regressions and Fama-Macbeth regressions are very similar, which suggests that our results are not sensitive to the choice of regression methodology.
} 
Table 4 Forecasting Stock Return Volatility

\begin{tabular}{|c|c|c|c|c|c|}
\hline & (1) & (2) & (3) & (4) & (5) \\
\hline & Volatility $_{t+1}$ & Volatility $_{t+1}$ & Volatility $_{t+1}$ & Volatility $_{t+1}$ & Volatility $_{t+1}$ \\
\hline \multirow[t]{2}{*}{$E V O L_{t}$} & $1.117 * * *$ & $0.401 * * *$ & $0.231 * * *$ & $0.244 * * *$ & $0.104 * * *$ \\
\hline & $(15.86)$ & (12.08) & $(9.83)$ & (6.94) & $(3.92)$ \\
\hline \multirow[t]{2}{*}{$I V O L_{t}$} & & & & $0.588 * * *$ & $0.496^{* * * *}$ \\
\hline & & & & (13.33) & (11.45) \\
\hline \multirow[t]{2}{*}{$H V O L_{t}$} & & $0.844 * * *$ & $0.555^{* * *}$ & $0.420 * * *$ & $0.140 * * *$ \\
\hline & & $(17.09)$ & (16.28) & $(9.54)$ & $(2.93)$ \\
\hline \multirow[t]{2}{*}{$\sigma(R O A)_{t}$} & & & $0.112 * * *$ & $0.082 *$ & $0.145^{* * *}$ \\
\hline & & & (3.19) & $(2.03)$ & $(3.57)$ \\
\hline \multirow[t]{2}{*}{ Size $_{t}$} & & & $-0.039 * * *$ & $-0.036^{* * *}$ & -0.003 \\
\hline & & & $(-6.35)$ & $(-5.30)$ & $(-0.29)$ \\
\hline \multirow[t]{2}{*}{ Book-to-price $_{t}$} & & & $0.021 * *$ & $0.015 *$ & $0.020 *$ \\
\hline & & & $(2.80)$ & $(1.96)$ & (1.99) \\
\hline \multirow[t]{2}{*}{ Earnings-to-price $_{t}$} & & & $-0.046^{* * *}$ & $-0.088 * * *$ & $-0.076^{* * *}$ \\
\hline & & & $(-3.17)$ & $(-7.15)$ & $(-6.65)$ \\
\hline \multirow[t]{2}{*}{ Loss Indicator $_{t}$} & & & $0.174 * * *$ & $0.098 * * *$ & $0.086^{* * *}$ \\
\hline & & & $(10.75)$ & $(6.82)$ & $(6.03)$ \\
\hline \multirow[t]{2}{*}{ Leverage $_{t}$} & & & $0.135^{* *}$ & $0.098 * *$ & $0.374 * * *$ \\
\hline & & & $(2.71)$ & (2.13) & $(6.21)$ \\
\hline \multirow[t]{2}{*}{$R O A_{t}$} & & & $-0.096 * * *$ & 0.015 & -0.017 \\
\hline & & & $(-5.29)$ & $(1.16)$ & $(-0.60)$ \\
\hline \multirow[t]{2}{*}{ Beta $_{t}$} & & & $0.039 * * *$ & $0.021 * *$ & -0.001 \\
\hline & & & $(4.78)$ & $(2.24)$ & $(-0.10)$ \\
\hline \multirow[t]{2}{*}{ Momentum $_{t}$} & & & 0.016 & $0.024 *$ & $0.029 * * *$ \\
\hline & & & $(1.38)$ & $(2.00)$ & $(3.03)$ \\
\hline Observations & 39,641 & 39,641 & 39,641 & 22,815 & 22,815 \\
\hline Adj. $\mathrm{R}^{2}$ & 0.230 & 0.507 & 0.563 & 0.608 & 0.672 \\
\hline Industry F.E. & No & Yes & Yes & Yes & No \\
\hline Firm F.E. & No & No & No & No & Yes \\
\hline Year F.E. & No & Yes & Yes & Yes & Yes \\
\hline
\end{tabular}

This table reports coefficient estimates and t-statistics from regressions of the natural logarithm of one-yearahead stock return volatility on expected volatility $(E V O L)$, implied volatility $(I V O L)$, historical volatility $(H V O L)$, and other firm characteristics at time $t$. Specifically, we estimate the following model using pooled regressions with various fixed effects (firm subscripts suppressed):

Volatility $_{t+1}=\gamma_{0}+\gamma_{1}$ EVOL $_{t}+\gamma_{2} \mathrm{IVOL}_{t}+\gamma_{3} \mathrm{HVOL}_{t}+\Sigma \gamma X_{t}+\varepsilon_{t+1}$

The reported t-statistics are based on standard errors clustered by firm and year. The asterisks *, **, and *** indicate statistical significance at the $10 \%, 5 \%$, and $1 \%$ levels (two-sided), respectively. See Appendix 1 for descriptions of variables

have predictive power for longer-term volatility as well. On the other hand, if forecasting over the longer horizon is more difficult for managers, this would reduce the information content of EVOL for long-term volatility. Although requiring long-term return volatility would reduce our sample size and test power and introduce survivorship bias, we think it is 


\section{a Compared to Model with $\mathrm{HVOL}$ and Firm Characteristics}

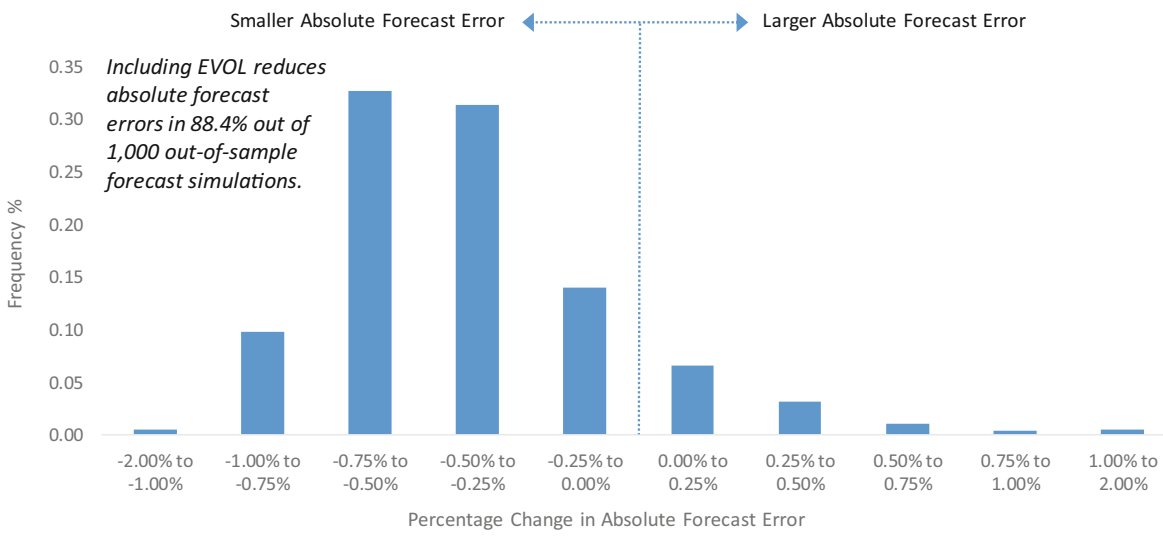

b Compared to Model with HVOL, IVOL, and Firm Characteristics

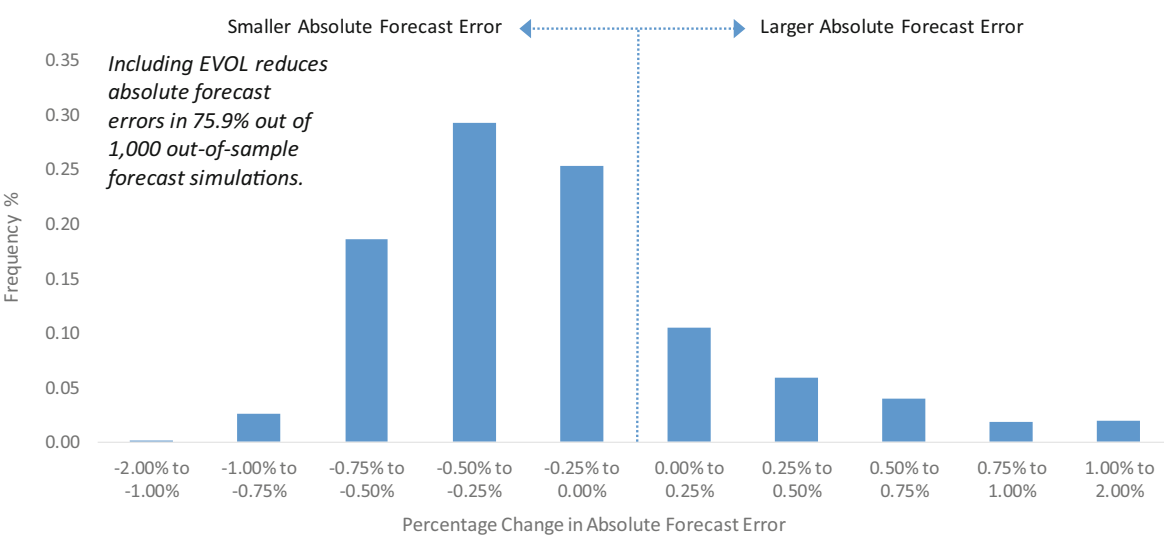

Fig. 2 Out-of-sample Forecasting Power of $\boldsymbol{E V O L}$. These figures plot the results of out-of-sample forecasting tests. We compare the out-of-sample absolute forecast errors from a model that includes expected volatility $(E V O L)$ against the out-of-sample absolute forecast errors from a model that excludes it. First, we randomly select 15 of the 20 years in our sample to estimate the coefficients from a baseline forecasting model and use the predicted values for the remaining five hold-out years to calculate absolute forecast errors. Absolute forecast errors are calculated as the unsigned differences between the realized one-year-ahead stock return volatility and the predicted one-year-ahead stock return volatility from the relevant forecasting model. Second, we include $E V O L$ in the baseline forecasting model, re-estimate the coefficients in the same estimation sample as before, and generate absolute forecast errors for the same remaining five hold-out years. We store the mean percentage change in the absolute forecast errors when the baseline forecasting model includes $E V O L$. Third, we repeat this process 1000 times to generate a distribution of percentage change in absolute forecast errors and plot this distribution to evaluate the performance of a forecasting model that includes EVOL. For Panel a, we use a baseline forecasting model that contains historical volatility $(H V O L)$, firm characteristics, industry fixed effects, and year fixed effects (i.e., column 3 from Table 4 but without $E V O L$ ). In Panel b, we use a baseline forecasting model that adds $I V O L$ to the model in Panel A (i.e., column 4 from Table 4 but without $E V O L$ )

interesting to evaluate the predictive power of $E V O L$ over horizons longer than one year. Therefore we also examine forecasting horizons of two, three, and four years ahead.

Table 5 reports the results from these longer-horizon forecasting tests for the natural logarithm of future stock return volatility. Columns 1 and 2 report the results for twoyear-ahead stock return volatility. Requiring another year of future stock return 
volatility reduces the sample to 35,382 observations (20,534 observations when also requiring $I V O L$ ). Specifically, we repeat the specifications in columns 3 and 4 of Table 4, using two-year-ahead instead of one-year-ahead stock return volatility. We also control for the one-year-ahead realizations of stock return volatility. In column 1, the coefficient on $E V O L$ continues to be positive and significant at 0.181 , suggesting that $E V O L$ captures forward-looking information beyond one year. ${ }^{14}$ In column 2, we also control for $I V O L$ and continue to find that $E V O L$ is significant. In columns 3 to 6 , we extend the horizon to three and four years ahead and include controls for additional realizations of stock return volatility. We find that $E V O L$ has significant explanatory power for longer-horizon stock return volatility, even after controlling for near-term realizations and $I V O L$. Overall, EVOL appears to capture both near-term and long-term stock return volatility.

Finally, we examine whether managers have private information about the effects of firm-specific decisions on volatility and how firm-specific exposures to common factors affect volatility. This could help us to better understand the predictive information content of EVOL. In untabulated results, we find that $E V O L$ is associated with both idiosyncratic volatility and the common component of volatility. ${ }^{15}$ The coefficient on $E V O L$ is significantly larger for idiosyncratic volatility than for the common component of volatility, which suggests that $E V O L$ captures firm-specific volatility relatively more.

Overall, we interpret these results as suggesting that $E V O L$ has predictive information content for future stock return volatility over short and long horizons. This predictive power is incremental to that of implied volatility, historical volatility, firm characteristics, industry fixed effects, and year fixed effects. The results also hold if we control for firm fixed effects. Importantly, EVOL is useful for out-of-sample forecasting of stock return volatility.

\subsection{Forecasting fundamentals using EVOL}

We now examine two channels through which $E V O L$ could predict stock return volatility: earnings volatility and future investment activities. We argue that $E V O L$ reflects managers' private information about strategic decisions and the implications of these decisions for future fundamentals. First, we examine the ability of EVOL to forecast earnings volatility. An association between EVOL and future earnings volatility would help clarify why $E V O L$ explains future stock return volatility. Second, we directly examine whether $E V O L$ is associated with future investment activities, such as mergers and acquisitions (M\&A) and R\&D intensity.

\footnotetext{
${ }^{14}$ If we do not control for one-year-ahead stock return volatility, the coefficient on $E V O L$ is even higher. The decline in the coefficient on EVOL after controlling for one-year-ahead volatility corroborates the Table 4 findings that $E V O L$ predicts one-year-ahead stock return volatility.

${ }^{15}$ We measure the idiosyncratic component as the natural logarithm of the standard deviation of residuals estimated from firm-level stock returns regressed on Fama-French-Carhart four-factor returns. We measure the common component as the natural logarithm of the standard deviation of predicted returns estimated using the same four-factor model, which would reflect firm-specific exposures to common factors. We replace the dependent variable in eq. (1) with either the one-year-ahead idiosyncratic volatility or the one-year-ahead common component of volatility.
} 


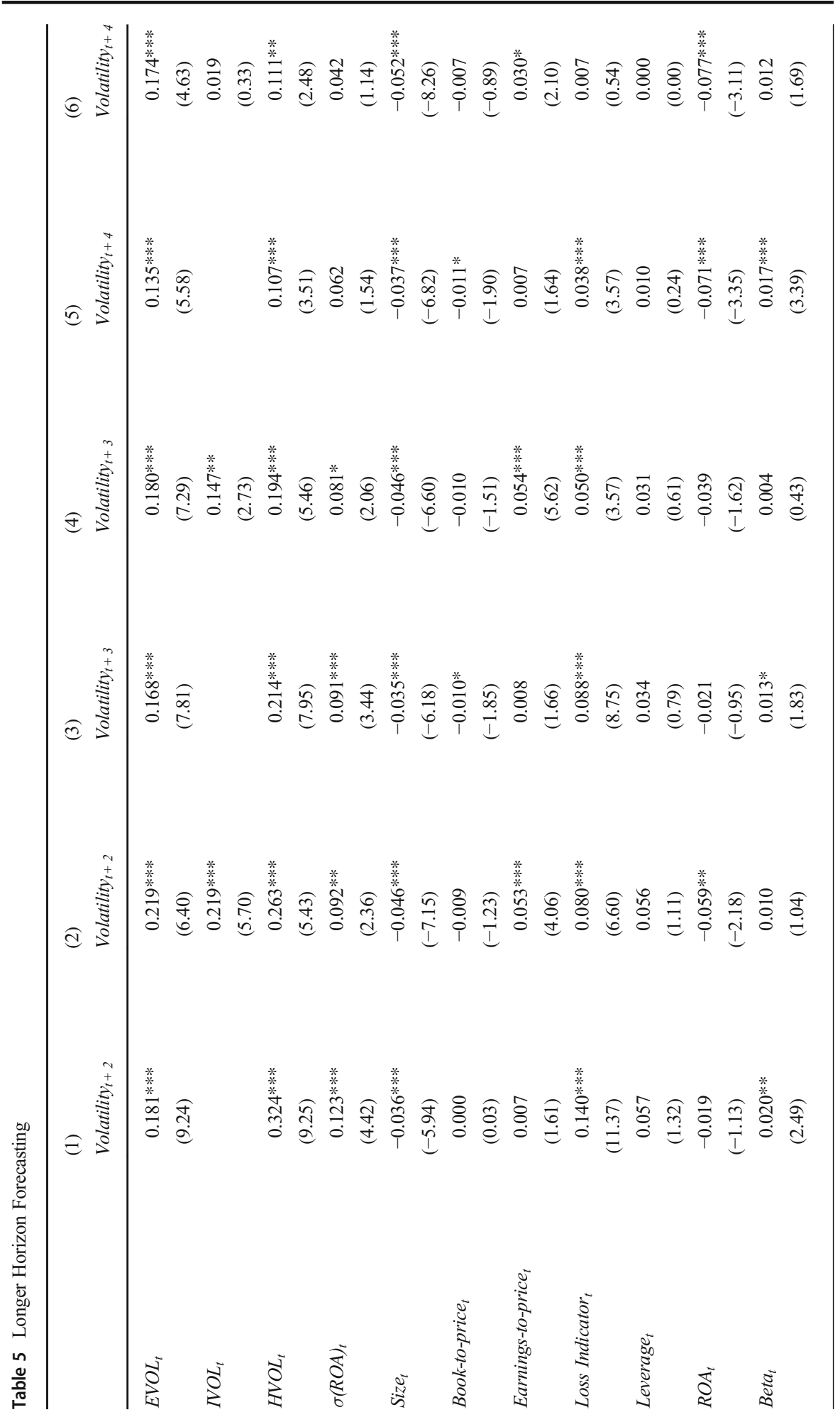




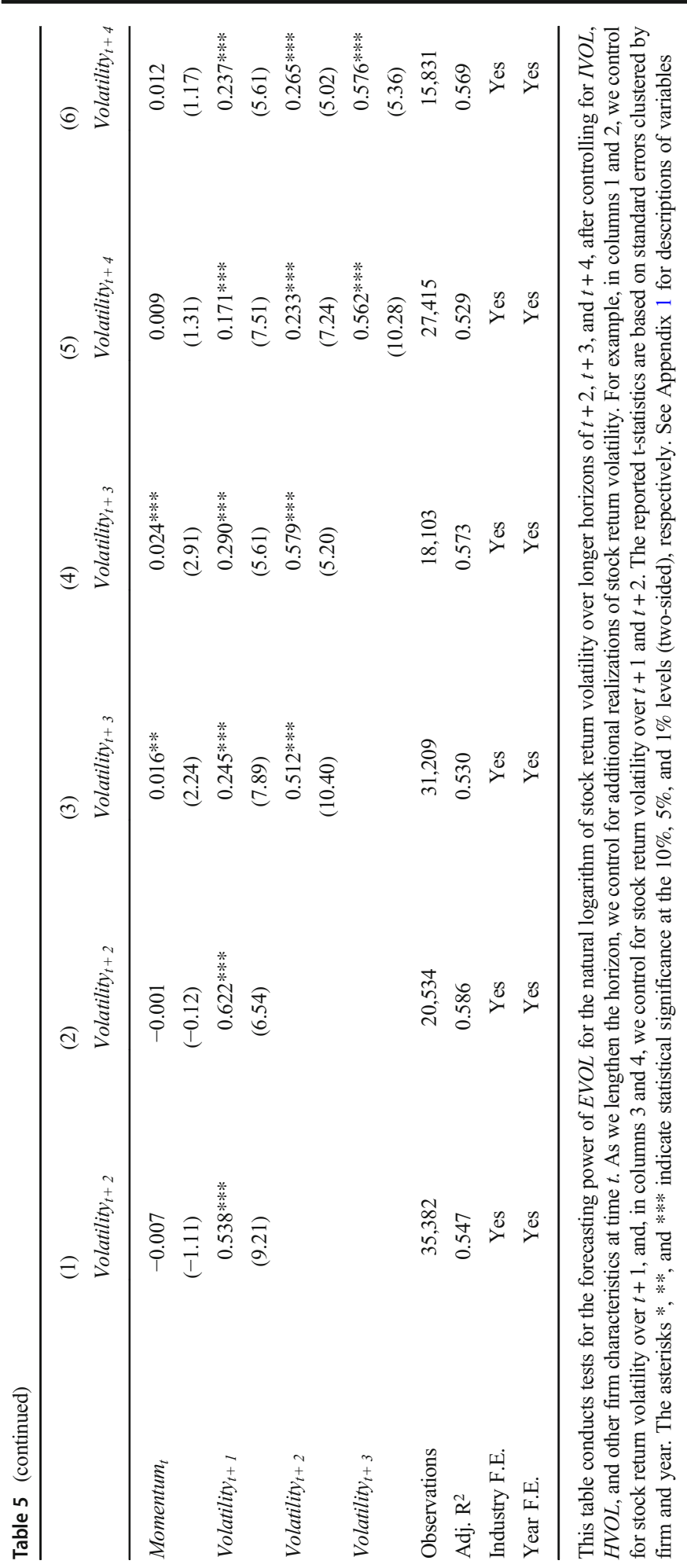




\subsubsection{Forecasting earnings volatility}

In Table 6, we test whether EVOL reflects managers' expectations of earnings volatility by estimating Eq. (2). Our sample declines slightly for this test, which is calculated as the standard deviation in quarterly return on assets over the next two years. ${ }^{16}$ If EVOL reflects managerial expectations of volatility in future firm fundamentals, we expect a positive and significant coefficient on EVOL. In Table 6, we report results both for the full and reduced sample after controlling for IVOL. In column 1 of Table 6 , the coefficient on $E V O L$ is positive and significant. In column 2, we control for $I V O L$ and find that EVOL remains significant, which is consistent with our conjecture. Finally, in column 3, we replace industry fixed effects with firm fixed effects and find that $E V O L$ remains positive and significant. All of these findings are consistent with $E V O L$ forecasting earnings volatility.

Next, we examine whether EVOL also has cross-sectional predictive power for extreme future earnings growth. In columns 4 to 7 of Table 6, we estimate Eq. (3) and report the results for EVOL's predictive power for Low Growth and for High Growth, both with and without controlling for $I V O L$. We find that EVOL is positively associated with the likelihood of both Low Growth and High Growth, which suggests that firms with higher $E V O L$ are more likely to experience extreme realizations of earnings growth, consistent with these firms having more volatile earnings generation. ${ }^{17}$ Managers who make strategic decisions with more uncertain outcomes may expect a greater likelihood of extreme earnings growth and therefore disclose higher $E V O L$. Overall, we interpret these results as being consistent with our conjecture that $E V O L$ reflects managers' private information about the implications of strategic decisions for future earnings volatility.

\subsubsection{Forecasting investment activities}

Next, we test for an association between $E V O L$ and future investment decisions. If managers expect to invest with uncertain payoffs and incorporate the implications of those decisions into their volatility forecasts, then $E V O L$ should be positively associated with future investment decisions. We use two measures of future investments over the next one and two fiscal years after the fiscal year-end when $E V O L$ is disclosed: an indicator variable for $\mathrm{M} \& \mathrm{~A}$ and $\mathrm{R} \& \mathrm{D}$ expenditures scaled by total assets. We control for current investment levels to account for persistence in corporate investment policies.

Table 7 reports the results. In column 1, consistent with our expectation, we find that firms with higher $E V O L$ are more likely to acquire or merge with another firm over the next two years. We report results both for the full sample and the reduced sample after controlling for $I V O L$. For example, in columns 2 and 4, the coefficients on EVOL for one-year-ahead and two-year-ahead M\&A are large and significant, even after controlling for IVOL. Similarly, in columns 5 and 8, higher EVOL is associated with higher

\footnotetext{
${ }^{16}$ In robustness tests, we find similar results if we measure standard deviation of earnings over the next four quarters or compute the standard deviation of quarterly changes scaled by assets, instead of earnings levels scaled by assets.

${ }^{17}$ While we cannot include firm fixed effects in the logistic regressions, we use OLS regressions with firm fixed effects and find qualitatively similar results.
} 


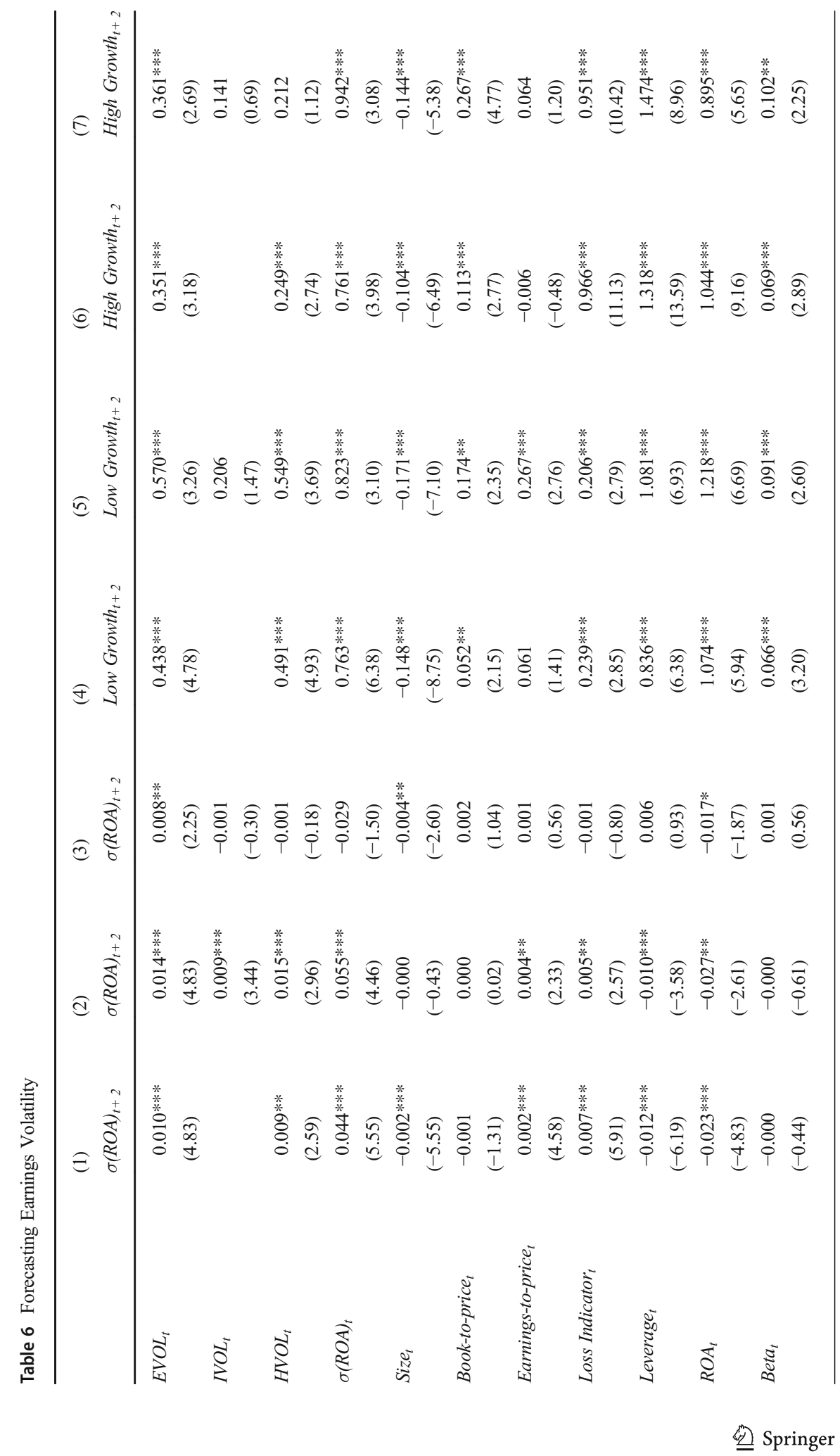




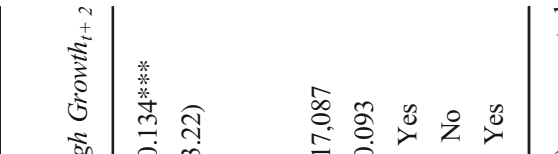

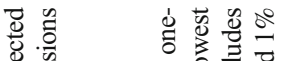

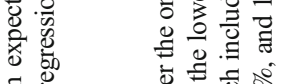

E 1 i.

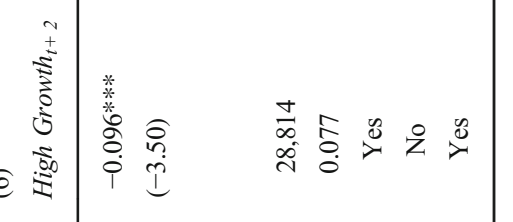

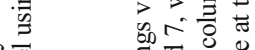

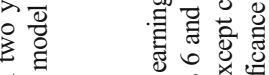

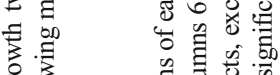

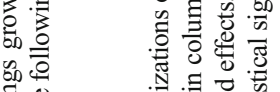

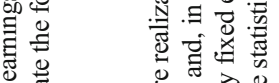

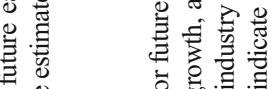

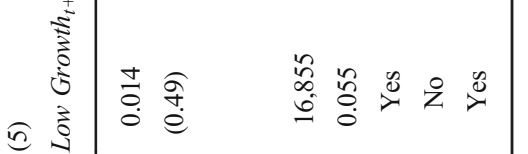

家

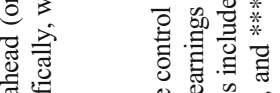

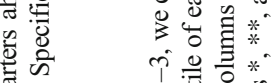

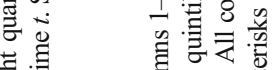

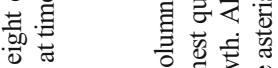

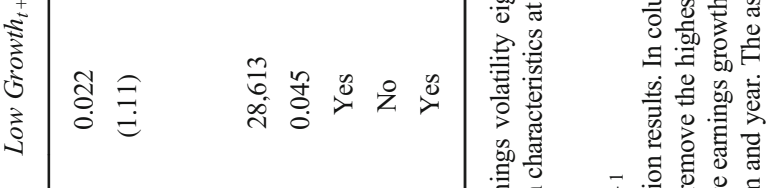

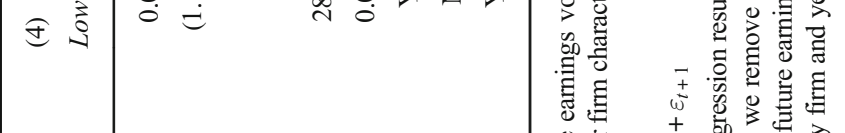

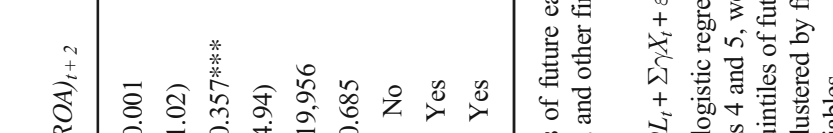

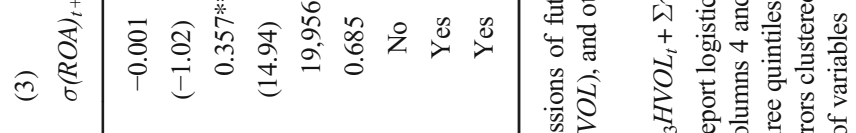

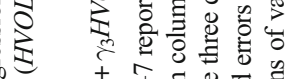

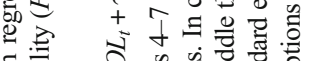

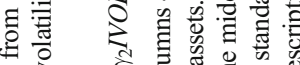

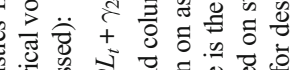

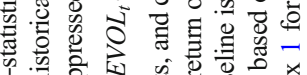

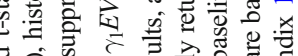

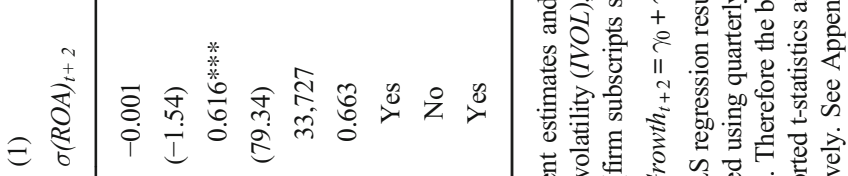

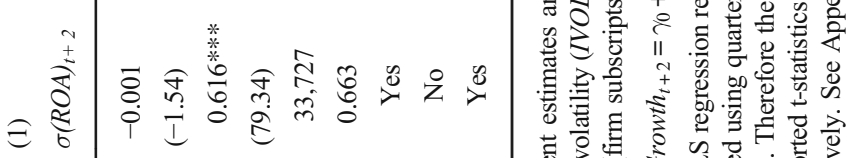

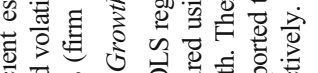

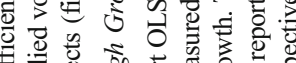

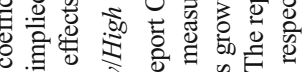

总

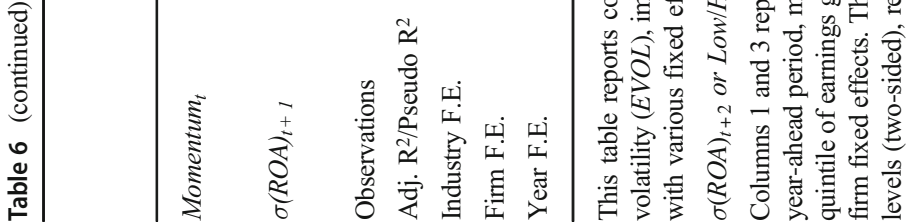


R\&D intensity over the next one and two years, even after controlling for $I V O L .{ }^{18}$ The effects are stronger for one-year-ahead investments than for two-year-ahead investments, which may reflect the greater difficulty of longer-term forecasting. Overall, these results suggest that managers do incorporate, in EVOL, their investment-related uncertainty about future performance.

\subsection{Informativeness of $E V O L$ and earnings management incentives}

Having established that $E V O L$ contains predicts future return volatility, we now examine whether managerial incentives to manipulate earnings introduce biases in EVOL that reduce its predictive power. In Table 8, we test this conjecture in withinfirm analyses, using five proxies that capture variation in managerial incentives to manipulate earnings. Panel A (Panel B) reports results for the natural logarithm of oneyear-ahead (two-year-ahead) stock return volatility.

First, we examine whether managerial incentives change around the 2006 switch from SFAS 123 to SFAS $123 R$ (Post 123R). This removed firms' option to use the intrinsic value method to calculate employee stock option compensation expense. Since the intrinsic value method does not rely on EVOL, managers before $123 \mathrm{R}$ may have had fewer incentives to use stock option expense to manage earnings. After 123R, all firms have to use the fair value method, which relies on $E V O L$ to recognize stock option expenses. We therefore expect that, after $123 \mathrm{R}$, managers have stronger incentives to bias $E V O L$ downward to reduce stock option expense. In column 1 of Table 8 (Panel A), we interact an indicator variable for the post-123R period (Post 123R) with $E V O L$ and find that the within-firm explanatory power of $E V O L$ for future stock return volatility indeed shrinks after this change. The estimated coefficient on the interaction of EVOL with Post $123 R$ is negative and significant.

Second, we examine the level of employee stock option grants (Option Grants). Aboody et al. (2006) find that managers strategically bias EVOL downward to increase reported earnings. A higher level of option grants indicates that managers have stronger incentives to do this. Consistent with our expectation, in column 2 of Table 8 (Panel A), we find the estimated coefficient on the interaction of EVOL with Option Grants is negative and significant, indicating a decrease in the explanatory power of EVOL.

Third, we examine instances of small profits to identify managerial incentives to avoid losses through earnings manipulation. Burgstahler and Dichev (1997) and Degeorge et al. (1999) find that firms have incentives to manage reported earnings to avoid losses, resulting in unusually high frequencies of small positive income. In our sample, we observe a distribution of small positive income (i.e., ROA between $0 \%$ and $1 \%$ ) that resembles that of prior work and use an indicator variable (Small Profit) to identify these observations. To the extent that managerial incentives to report small profits lead managers to bias EVOL downward, the informativeness of EVOL could be reduced. Consistent with our expectation, in column 3 of Table 8 (Panel A), we find that the coefficient on the interaction between EVOL and Small Profit is negative and significant.

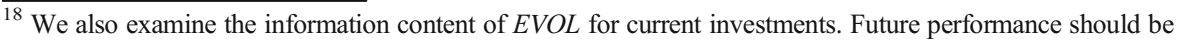
affected by current investment decisions, and the implications of these decisions for future volatility might be reflected in $E V O L$. Consistent with our expectations, we find that $E V O L$ is positively associated with M\&A and $R \& D$ intensity during the current year (untabulated).
} 


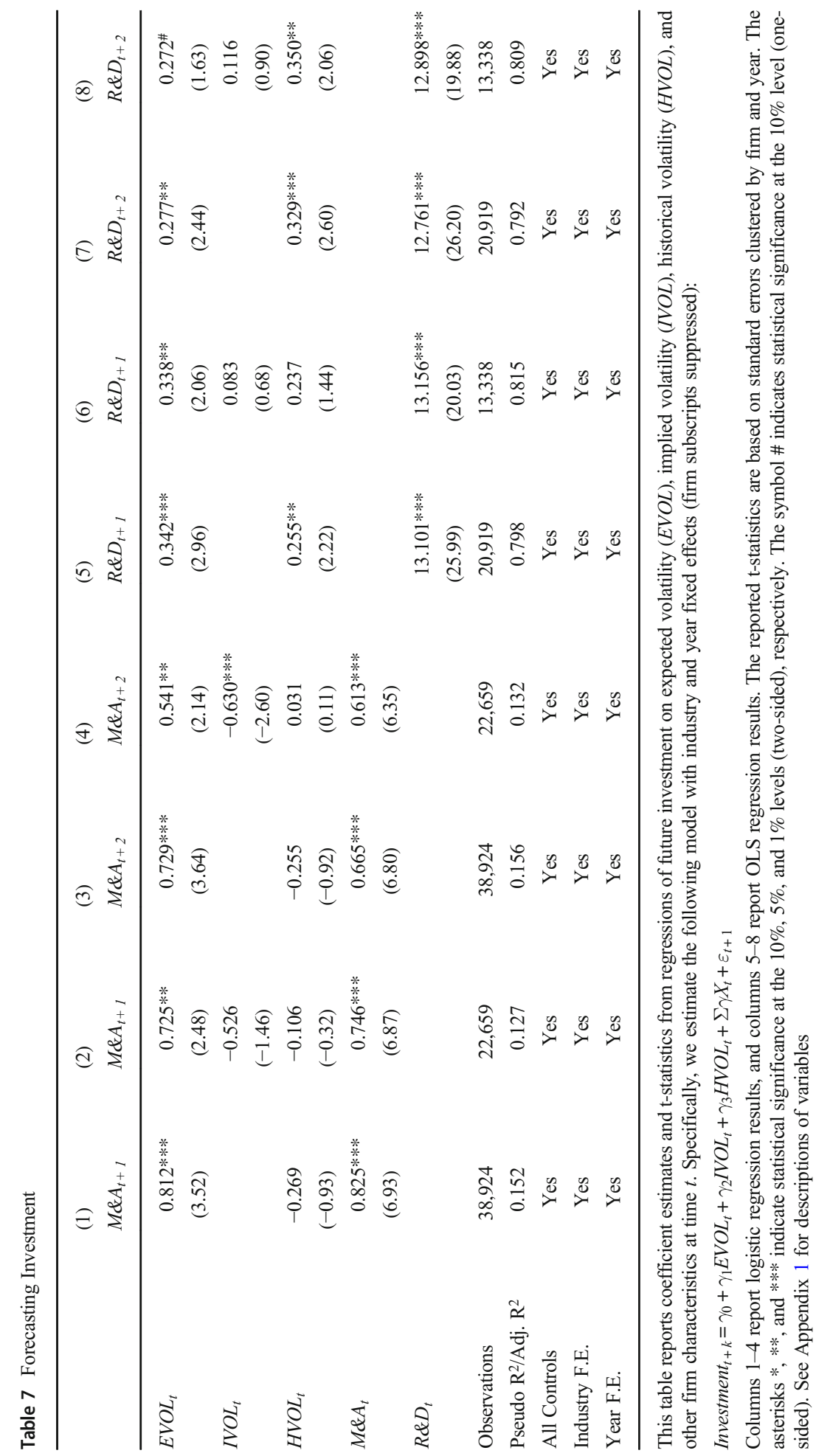


Table 8 EVOL and Earnings Management Incentives

Panel A: One-Year-Ahead Stock Return Volatility

(1) (2) (3) (4) (5)

Volatility $_{t+1}$ Volatility $_{t+1} \quad$ Volatility $_{t+1} \quad$ Volatility $_{t+1} \quad$ Volatility $_{t+1}$

$\begin{array}{ll}\text { EVOL }_{t} & 0.297 * * * \\ & (4.30) \\ \text { EVOL }_{t} \times \text { Post } 123 R_{t} & -0.404 * * * \\ & (-3.78)\end{array}$

$-4.392 * *$

$(-2.35)$

$-0.177 * *$

$(-2.18)$

$\mathrm{EVOL}_{t} \times$ Small Miss $_{t}$

$\mathrm{EVOL}_{t} \times$ Small Beat $_{t}$

$0.131 * * * \quad 0.089$ ***

$0.075 * *$

$0.154 *$

(2.97)

(2.49)

(2.00)

$\mathrm{EVOL}_{t} \times$ Option Grants $_{t}$

$\mathrm{EVOL}_{t} \times$ Small Profit $_{t}$

\begin{tabular}{|c|c|c|c|c|}
\hline & & & $-0.146^{\#}$ & \\
\hline & & & $(-1.37)$ & \\
\hline & & & 0.052 & \\
\hline & & & $(0.97)$ & \\
\hline & & & & $-0.170 * *$ \\
\hline & & & & $(-2.25)$ \\
\hline $0.511 * * *$ & $0.463 * * *$ & $0.526 * * *$ & $0.526 * * *$ & $0.747 * * *$ \\
\hline (12.04) & (11.18) & (12.27) & (13.21) & (6.22) \\
\hline 0.042 & $0.112 * *$ & 0.083 & 0.090 & -0.016 \\
\hline$(0.58)$ & (2.33) & (1.29) & $(1.46)$ & $(-0.11)$ \\
\hline 22,815 & 21,642 & 22,815 & 21,046 & 4,347 \\
\hline 0.675 & 0.649 & 0.672 & 0.673 & 0.689 \\
\hline Yes & Yes & Yes & Yes & Yes \\
\hline Yes & Yes & Yes & Yes & Yes \\
\hline Yes & Yes & Yes & Yes & Yes \\
\hline Yes & Yes & Yes & Yes & Yes \\
\hline
\end{tabular}

Panel B: Two-Year-Ahead Stock Return Volatility

$E V O L_{t} \times G-$ Index $_{t}$

$\mathrm{IVOL}_{t}$

$\mathrm{HVOL}_{t}$

(1)

(2)

(3)

(4)

(5)

Volatility $_{t+2}$

Volatility $_{t+2}$

Volatility $_{t+2}$

Volatility $_{t+2}$

Volatility $_{t+2}$

EVOL $_{t}$

$0.318 * * *$

$0.137 * *$

$0.094 * * *$

$0.084 * *$

$0.183 *$

(3.03)

(2.79)

(2.87)

(2.82)

(2.16)

$$
(-2.83)
$$

$$
\begin{array}{cc}
\text { EVOL }_{t} \times \text { Option }_{\text {Grants }} & -6.873^{* * *} \\
& (-2.10)
\end{array}
$$

$\mathrm{EVOL}_{t} \times$ Small Profit ${ }_{t}$

$$
\begin{aligned}
& -0.264 * * \\
& (-2.19)
\end{aligned}
$$

$\mathrm{EVOL}_{t} \times$ Small Miss $_{t}$

$$
\begin{gathered}
-0.167 \# \\
(-1.63) \\
0.068 \\
(1.09)
\end{gathered}
$$


Table 8 (continued)

\begin{tabular}{lccccc}
\hline EVOL $L_{t} \times$ G-Index & & & & -0.139 \\
& & & & & $(-1.42)$ \\
VOL $_{t}$ & $0.239 * * *$ & $0.219 * * *$ & $0.258^{* * *}$ & $0.245^{* * *}$ & $0.467 * * *$ \\
& $(4.32)$ & $(4.81)$ & $(4.85)$ & $(4.71)$ & $(3.98)$ \\
HVOL $_{t}$ & -0.090 & 0.005 & -0.041 & -0.040 & -0.152 \\
& $(-0.88)$ & $(0.09)$ & $(-0.46)$ & $(-0.42)$ & $(-1.00)$ \\
Observations & 20,534 & 18,599 & 20,534 & 18,956 & 4,200 \\
Adj. R & 0.648 & 0.621 & 0.645 & 0.645 & 0.642 \\
Main Effects Included & Yes & Yes & Yes & Yes & Yes \\
All Controls & Yes & Yes & Yes & Yes & Yes \\
Firm F.E. & Yes & Yes & Yes & Yes & Yes \\
Year F.E. & Yes & Yes & Yes & Yes & Yes \\
\hline
\end{tabular}

This table reports cross-sectional variation in coefficient estimates of EVOL based on interactions with different proxies for earnings management incentives. Specifically, we estimate the following model using pooled regressions with firm and year fixed effects (firm subscripts suppressed):

Volatility $_{t+1}=\gamma_{0}+\gamma_{1}$ EVOL $_{t}+\gamma_{2} E_{t}+\gamma_{3} E_{V O L} \times E M_{t}+\gamma_{4} I V O L_{t}+\gamma_{5} H V O L_{t}+\Sigma \gamma X_{t}+\varepsilon_{t+1}$

In Panel $\mathrm{A}$, the dependent variable is the natural logarithm of one-year-ahead stock return volatility, and, in Panel B, the dependent variable is the natural logarithm of two-year-ahead stock return volatility. EM is the proxy for earnings management incentives. The reported t-statistics are based on standard errors clustered by firm and year. The asterisks *, **, and *** indicate statistical significance at the $10 \%, 5 \%$, and $1 \%$ levels (twosided), respectively. The symbol \# indicates statistical significance at the $10 \%$ level (one-sided). See Appendix 1 for descriptions of all other variables

Fourth, we use proximity of reported earnings to a target earnings level (Small Miss or Small Beat) (Degeorge et al. 1999; McAnally et al. 2008). To identify the target earnings level, we use the consensus EPS forecast from I/B/E/S. We use an indicator variable, Small Miss, to identify reported EPS that is one cent below the consensus EPS forecast, and another indicator variable, Small Beat, to identify reported EPS that is up to one cent above it. Small Beat captures managerial incentives to inflate earnings; Small Miss may capture managerial incentives to deflate earnings to lower strike prices (McAnally et al. 2008). We expect either of these incentives to introduce biases that could reduce the informativeness of EVOL. Consistent with our expectation, in column 4 of Table 8 (Panel A), the coefficient on the interaction between EVOL and Small Miss is negative and significant. However, the coefficient on the interaction between EVOL and Small Beat is insignificant.

Finally, we examine the strength of firms' corporate governance structure as a proxy for firms' monitoring environment. Weaker monitoring could facilitate managers' manipulation of earnings upward by understating EVOL. Following Aboody et al. (2006) we use the governance score from Gompers et al. (2003) to identify managerial opportunity to understate stock option expenses. G-Index is an indicator variable that identifies firms with a governance score that is above the sample median (i.e., weaker corporate governance), which could reduce the informativeness of EVOL. Consistent with our expectation, in column 5 of Table 8 (Panel A), the coefficient on the interaction between $E V O L$ and G-Index is negative and significant. 
Overall, we find that the incremental predictive power of $E V O L$ is significantly attenuated with these proxies for earnings management incentives. This finding is consistent with biases reducing the information content in EVOL. It also raises the question of whether the relation between $E V O L$ and future stock return volatility is reversed when earnings management incentives are high. To answer this question, we test whether the sum of the coefficients for $E V O L$ and the interaction term of $E V O L$ with each earnings management proxy differs significantly from zero. We find that the sum of these coefficients is positive and significant for Small Profit but indistinguishable from zero for Post 123R, Option Grants, Small Miss, and GIndex at conventional levels. Finally, in Panel B of Table 8, we change the dependent variable to the natural logarithm of two-year-ahead stock return volatility and find similar inferences.

\subsection{Additional analyses}

So far, we have documented that EVOL has forward-looking information content for future realizations of volatility, both over the near and long term. We have also provided evidence consistent with EVOL reflecting managers' private information about future fundamentals and investments. And we have shown that the informativeness of EVOL is lower when managers may have earnings management incentives, which could lead them to bias EVOL. We now provide additional evidence to corroborate and test the sensitivity of our main results. Specifically, we (1) control for alternative measures of uncertainty, (2) examine whether EVOL explains returns to a volatility straddle, and (3) consider alternative specifications.

\subsubsection{Alternative measures of uncertainty}

We have shown that EVOL has predictive power for future stock return volatility that is incremental to that of implied volatility, historical volatility, firm characteristics, and various fixed effects. In this subsection, we examine the sensitivity of our inferences to including numerous alternative measures of uncertainty: a market-based measure embedded in analyst forecasts, accountingbased measures, and disclosure-based measures proposed in the literature (Campbell et al. 2014; Sridharan 2015; Correia et al. 2018). Table 9 presents the results for the natural logarithm of one-year-ahead stock return volatility (Panel A) and two-year-ahead stock return volatility (Panel B).

We begin by considering a market-based measure of uncertainty proxied by analyst EPS forecast dispersion. Analyst forecast dispersion is measured as the coefficient of variation in EPS forecasts from I/B/E/S (i.e., standard deviation in EPS estimates across analysts, scaled by mean consensus EPS) for the one-year-ahead period. In column 1, the coefficient on EVOL remains positive and significant. We also find that analyst forecast dispersion is significantly associated with future stock return volatility. The results suggest that EVOL captures private information not reflected in market expectations.

We then control for several accounting-based measures of uncertainty. Based on the accounting framework of Penman et al. (2018), expected returns can be 
Table 9 Alternative Measures of Uncertainty

\begin{tabular}{|c|c|c|c|c|c|c|}
\hline \multicolumn{7}{|c|}{ Panel A: One-Year-Ahead Stock Return Volatility } \\
\hline & (1) & (2) & (3) & (4) & (5) & (6) \\
\hline & Volatility $_{t+1}$ & Volatility $_{t+1}$ & Volatility $_{t+1}$ & Volatility $_{t+1}$ & Volatility $_{t+1}$ & Volatility $_{t+1}$ \\
\hline$E V O L_{t}$ & $0.284 * * *$ & $0.227^{* * *}$ & $0.212 * * *$ & $0.181 * * *$ & $0.185^{* * *}$ & $0.055^{\#}$ \\
\hline & $(7.21)$ & $(10.34)$ & $(8.59)$ & $(4.56)$ & $(3.57)$ & $(1.63)$ \\
\hline CV(Analyst Estimates) ${ }_{t}$ & $0.066^{* * *}$ & & & & $0.040^{* *}$ & $0.040 * * *$ \\
\hline & $(6.13)$ & & & & $(2.50)$ & $(3.39)$ \\
\hline$\sigma(E / P)_{t}$ & & -0.002 & & & -0.005 & $0.030 * *$ \\
\hline & & $(-0.24)$ & & & $(-0.48)$ & (3.03) \\
\hline$\sigma(\Delta B / P)_{t}$ & & $0.068 * * *$ & & & 0.027 & $0.027 * * *$ \\
\hline & & $(3.61)$ & & & $(1.02)$ & $(3.22)$ \\
\hline$\sigma\left(\right.$ RNOA quantile $_{t}$ & & & $0.137 * * *$ & & 0.112 & -0.016 \\
\hline & & & (3.14) & & $(1.62)$ & $(-0.25)$ \\
\hline Risk Factors $_{t}$ & & & & $0.037 * * *$ & $0.036 * * *$ & -0.000 \\
\hline & & & & (7.57) & $(3.83)$ & $(-0.02)$ \\
\hline$I V O L_{t}$ & & & & & $0.564 * * *$ & $0.463 * * *$ \\
\hline & & & & & $(10.54)$ & $(9.05)$ \\
\hline$H V O L_{t}$ & $0.604 * * *$ & $0.535^{* * *}$ & $0.605 * * *$ & $0.568 * * *$ & $0.509 * * *$ & 0.107 \\
\hline & (10.95) & (15.88) & (13.69) & $(10.40)$ & $(5.50)$ & $(1.16)$ \\
\hline Observations & 26,678 & 38,608 & 35,239 & 20,173 & 10,919 & 10,919 \\
\hline Adj. $R^{2}$ & 0.583 & 0.564 & 0.553 & 0.549 & 0.577 & 0.657 \\
\hline All Controls & Yes & Yes & Yes & Yes & Yes & Yes \\
\hline Industry F.E. & Yes & Yes & Yes & Yes & Yes & No \\
\hline Firm F.E. & No & No & No & No & No & Yes \\
\hline Year F.E. & Yes & Yes & Yes & Yes & Yes & Yes \\
\hline
\end{tabular}

Panel B: Two-Year-Ahead Stock Return Volatility

(1)

(2)

(3)

(4)

(5)

(6)

Volatility $_{t+2}$ Volatility $_{t+2}$ Volatility $_{t+2}$ Volatility $_{t+2}$ Volatility $_{t+2}$ Volatility $_{t+2}$

\begin{tabular}{|c|c|c|c|c|c|c|}
\hline$E V O L_{t}$ & $\begin{array}{l}0.307 * * * \\
(9.37)\end{array}$ & $\begin{array}{l}0.228 * * * \\
(9.80)\end{array}$ & $\begin{array}{l}0.220^{* * * *} \\
(10.44)\end{array}$ & $\begin{array}{l}0.228 * * * \\
(7.91)\end{array}$ & $\begin{array}{l}0.266^{* * * *} \\
(6.78)\end{array}$ & $\begin{array}{l}0.077^{*} \\
(2.01)\end{array}$ \\
\hline$C V(\text { Analyst Estimates })_{t}$ & $\begin{array}{l}0.074^{* * * *} \\
(6.65)\end{array}$ & & & & $\begin{array}{l}0.065^{* * * *} \\
(3.20)\end{array}$ & $\begin{array}{l}0.058^{* * * *} \\
(4.41)\end{array}$ \\
\hline$\sigma(E / P)_{t}$ & & $\begin{array}{l}-0.030 * * * \\
(-4.08)\end{array}$ & & & $\begin{array}{l}-0.026^{* * *} \\
(-2.30)\end{array}$ & $\begin{array}{l}-0.004 \\
(-0.24)\end{array}$ \\
\hline$\sigma(\Delta B / P)_{t}$ & & $\begin{array}{l}0.037 * * \\
(2.15)\end{array}$ & & & $\begin{array}{l}-0.009 \\
(-0.35)\end{array}$ & $\begin{array}{c}0.002 \\
(0.09)\end{array}$ \\
\hline$\sigma\left(R_{N O A}\right.$ quantile $_{t}$ & & & $\begin{array}{l}0.120 * * \\
(2.34)\end{array}$ & & $\begin{array}{c}0.120 \\
(1.45)\end{array}$ & $\begin{array}{l}-0.126 \\
(-1.70)\end{array}$ \\
\hline Risk Factors $_{t}$ & & & & $\begin{array}{l}0.037^{* * * *} \\
(6.86)\end{array}$ & $\begin{array}{l}0.034^{* * * *} \\
(3.71)\end{array}$ & $\begin{array}{l}-0.022 \\
(-1.17)\end{array}$ \\
\hline$I V O L_{t}$ & & & & & $\begin{array}{l}0.364 * * * \\
(4.44)\end{array}$ & $\begin{array}{l}0.149^{* *} \\
(2.75)\end{array}$ \\
\hline
\end{tabular}


Table 9 (continued)

\begin{tabular}{lcccccc}
\hline HVOL & & & & & & \\
& $0.493 * * *$ & $0.461 * * *$ & $0.507 * * *$ & $0.404 * * *$ & $0.347 * * *$ & -0.203 \\
Observations & $(9.33)$ & $(12.18)$ & $(12.07)$ & $(8.63)$ & $(3.40)$ & $(-1.74)$ \\
Adj. R & 24,058 & 34,497 & 31,666 & 17,882 & 9,797 & 9,797 \\
All Controls & 0.533 & 0.507 & 0.497 & 0.484 & 0.511 & 0.649 \\
Industry F.E. & Yes & Yes & Yes & Yes & Yes & Yes \\
Firm F.E. & Yes & Yes & Yes & Yes & Yes & No \\
Year F.E. & No & No & No & No & No & Yes \\
\hline
\end{tabular}

This table examines the information content of expected volatility $(E V O L)$ for future stock return volatility incremental to alternative firm-level measures of uncertainty, while controlling for implied volatility (IVOL), historical volatility $(H V O L)$, and other firm characteristics at time $t$. Specifically, we estimate the following model using pooled regressions with various fixed effects (firm subscripts suppressed):

Volatility $_{t+1}=\gamma_{0}+\gamma_{1}$ EVOL $_{t}+\gamma_{2}$ Uncertainty $_{t}+\gamma_{3}$ IVOL $_{t}+\gamma_{4} H_{V O L}+\Sigma \gamma X_{t}+\varepsilon_{t+1}$

In Panel $\mathrm{A}$, the dependent variable is the natural logarithm of one-year-ahead stock return volatility, and, in Panel B, the dependent variable is the natural logarithm of two-year-ahead stock return volatility. Uncertainty is an alternative firm-level measure of uncertainty. Columns 1-5 include industry fixed effects, and column 6 includes firm fixed effects. The reported t-statistics are based on standard errors clustered by firm and year. The asterisks *,**, and $* * *$ indicate statistical significance at the $10 \%, 5 \%$, and $1 \%$ levels (two-sided), respectively. The symbol \# indicates statistical significance at the $10 \%$ level (one-sided). See Appendix 1 for descriptions of variables

decomposed into the expected earnings yield and the expected change in the premium of price over book value of equity. Sridharan (2015) finds that the standard deviation of these accounting-based variables, $\sigma(E / P)$ and $\sigma(\Delta B / P)$, can predict stock return volatility. Therefore we re-estimate Eq. (1) after including these variables. In column 2, we find that the coefficient on EVOL remains significantly positive, the coefficient on $\sigma(E / P)$ is insignificant, and the coefficient on $\sigma(\Delta B / P)$ is positive and significant.

For another accounting-based measure of uncertainty, we follow Correia et al. (2018) and use the dispersion in forecasted quantiles of RNOA (see their Appendix III). Specifically, we estimate annual cross-sectional quantile regressions of current RNOA on lagged RNOA, an earnings loss indicator (Loss), the interaction of lagged RNOA and Loss, accruals scaled by net operating assets, a dividendpaying indicator, and dividend payout ratio. Using annual coefficients from the quantile regressions, we forecast percentiles of RNOA for each firm and then calculate the dispersion in these forecasted percentiles, that is, $\sigma$ (RNOA quantile). In column 3 , the coefficient on $E V O L$ remains positive and significant when we include this alternative measure of uncertainty. The coefficient on $\sigma(R N O A$ quantile) is also positive and significant.

Next, we consider a measure of uncertainty based on firm risk factor disclosures. To construct this measure, we use the logarithm of the total number of words in the risk factor disclosure section of 10-Ks (Risk Factors), following Campbell et al. (2014). In column 4, after controlling for Risk Factors, we continue to find that EVOL has incremental predictive power for stock return volatility. We find that the coefficient on Risk Factors is also positive and significant. 
In column 5, we examine whether the power of $E V O L$ is subsumed by including all of these alternative measures of uncertainty in our model as well as by controlling for $I V O L$. We find the coefficient on EVOL continues to be positive and significant, which suggests that $E V O L$ has forecasting power incremental to that of these alternative measures of uncertainty. ${ }^{19}$ In column 6 , we replace industry fixed effects with firm fixed effects and find that the coefficient on $E V O L$ remains positive and significant at the $10 \%$ level (one-sided). Finally, in Panel B of Table 9, we examine the incremental predictive power of $E V O L$ for two-year-ahead stock return volatility and find similar inferences.

\subsubsection{Volatility straddle returns}

Next, we examine whether the incremental information in EVOL is incorporated into option prices. Research has used the association between volatility straddle returns and volatility signals to evaluate the informativeness of these signals and whether they are incorporated in option prices (Goyal and Saretto 2009; Goodman et al. 2018). A positive association between EVOL and volatility straddle returns would be additional evidence of the incremental information content of EVOL. However, EVOL may not be reflected in option prices due to market frictions (e.g., illiquidity).

To test whether EVOL has predictive information content for monthly volatility straddle returns (Ret $\left.{ }^{\text {Straddle }}\right)$, we form a long volatility straddle by taking a long position in both an at-the-money (ATM) call and an ATM put option of equivalent maturity and measure the returns for this straddle (see Appendix 1 for details). Table 10 reports the results for volatility straddles formed each month after the $10-\mathrm{K}$ filing date until the month before the next $10-\mathrm{K}$ filing date (i.e., 11 months). In column 1, we control for IVOL to identify the incremental predictive power of EVOL. We use traded options data for this test and measure $I V O L$ as the average implied volatility for the ATM call and ATM put options used in the straddle (i.e., $I V O L^{\text {Traded }}$ ). In column 2, we focus on the difference between $E V O L$ and $I V O L^{\text {Traded }}$, which we interpret as the incremental information in EVOL not already captured by $I V O L^{\text {Traded }}$. In both columns, we find that $E V O L$ contains incremental information for volatility straddle returns.

We also control for an alternative volatility signal proposed by Goyal and Saretto (2009): the difference between HVOL and IVOL Traded. In column 3, we continue to find that $E V O L-I V O L^{\text {Traded }}$ is positively associated with volatility straddle returns, incremental to the difference between $H V O L$ and $I V O L^{\text {Traded }}$. In column 4 , we include transaction costs at $50 \%$ of the quoted bid-ask spread and find that $E V O L$ continues to be positively associated with volatility straddle returns. Finally, in column 5 , we replace industry fixed effects with firm fixed effects and find that our inferences regarding EVOL remain unchanged. Overall,

\footnotetext{
${ }^{19}$ We have also considered the analyst risk rating measures from Lui et al. (2007, 2012). Their hand-collected data covers a limited set of firms over the 1999-2006 period. Hence we can only match their analyst risk rating data for a small fraction $(6.7 \%)$ of our sample. In untabulated results, we re-estimate the models in columns 3 and 4 of Table 4 , after controlling for analyst risk ratings in this subsample, and find that EVOL has incremental predictive power for volatility.
} 
Table 10 Volatility Straddle Returns

\begin{tabular}{|c|c|c|c|c|c|}
\hline & (1) & (2) & (3) & (4) & (5) \\
\hline & Ret ${ }^{\text {Straddle }}$ & Ret $t^{\text {Straddle }}$ & Ret ${ }^{\text {Straddle }}$ & $\operatorname{Ret}_{50 \%}^{\text {Straddle }}$ & $\operatorname{Ret}_{50 \%}^{\text {Straddle }}$ \\
\hline \multirow[t]{2}{*}{$E V O L_{t}$} & $0.057 * *$ & & & & \\
\hline & $(2.15)$ & & & & \\
\hline \multirow[t]{2}{*}{$I V O L_{t}^{\text {Traded }}$} & $-0.201 * * *$ & & & & \\
\hline & $(-4.08)$ & & & & \\
\hline \multirow[t]{2}{*}{$E V O L_{t}-I V O L_{t}^{\text {Traded }}$} & & $0.143 * * *$ & $0.102 * * *$ & $0.094 * * *$ & $0.125 * * *$ \\
\hline & & $(4.67)$ & (3.79) & $(3.48)$ & $(4.12)$ \\
\hline \multirow[t]{2}{*}{$H V O L_{t}-I V O L_{t}^{\text {Traded }}$} & & & $0.054^{* *}$ & $0.052 * *$ & 0.063 \\
\hline & & & $(2.05)$ & $(2.07)$ & (1.49) \\
\hline \multirow[t]{2}{*}{$H V O L_{t}$} & -0.015 & $-0.069 * * *$ & & & \\
\hline & $(-0.55)$ & $(-2.67)$ & & & \\
\hline Observations & 54,870 & 54,870 & 54,870 & 54,870 & 54,870 \\
\hline Adj. $R^{2}$ & 0.010 & 0.009 & 0.009 & 0.009 & 0.008 \\
\hline All Controls & Yes & Yes & Yes & Yes & Yes \\
\hline Industry F.E. & Yes & Yes & Yes & Yes & No \\
\hline Firm F.E. & No & No & No & No & Yes \\
\hline Year F.E. & Yes & Yes & Yes & Yes & Yes \\
\hline
\end{tabular}

This table reports coefficient estimates from pooled regressions of the returns from a volatility straddle option trading strategy on expected volatility $(E V O L)$, implied volatility from traded options (IVOL Traded $)$, historical volatility $(H V O L)$, and firm characteristics at time $t$. Specifically, we estimate the following model with various fixed effects (firm subscripts suppressed):

$\operatorname{Ret}^{\text {Straddle }}=\gamma_{0}+\gamma_{1} E_{V O L}+\gamma_{2} I V O L_{t}^{\text {Traded }}+\gamma_{3} H_{V O L}+\Sigma \gamma X_{t}+\varepsilon_{t+1}$

$R e t^{\text {Straddle }}$ is volatility straddle return assuming option prices at the mid-point of the quoted bid-ask spread, while Ret $_{50 \%}^{\text {Straddle }}$ is volatility straddle return incorporating transaction costs at $50 \%$ of the quoted bid-ask spread. Columns 1-4 include industry fixed effects, and column 5 includes firm fixed effects. See Appendix 1 for further details and descriptions of other variables. The reported t-statistics are based on standard errors clustered by firm and year. The asterisks $*, * *$, and $* * *$ indicate statistical significance at the $10 \%, 5 \%$, and $1 \%$ levels (two-sided), respectively

we find that EVOL predicts volatility straddle returns, suggesting that option prices do not fully incorporate its information content.

\subsubsection{Robustness tests}

We also conduct a battery of robustness tests. The first test involves a change in data alignment. The accounting rules require firms to estimate $E V O L$ for the grant date fair value of stock options awarded during the year and to disclose EVOL at the end of the reporting period. In all our analyses, we therefore measure our variables at the fiscal year-end. Further, stock option expense is based on the amortization of previously estimated fair values and is reported in 10-Qs and 10-Ks. Despite the accounting rules, however, EVOL may reflect information that became available between the fiscal yearend and the $10-\mathrm{K}$ filing date. To address this concern, we re-estimate column 4 in Table 4 using future volatility, IVOL, and $H V O L$ measured at the $10-\mathrm{K}$ filing date (when that date is available). Our inferences about EVOL are unchanged. 
We also examine IVOL extracted from longer-dated options. Requiring longer-dated options inevitably skews the sample toward larger firms and significantly reduces the sample size. For each firm with available data, we extract $I V O L$ from options with oneyear (two-year) maturities and then assess the predictive power of $E V O L$ incremental to IVOL over the next one year (two years) by re-estimating column 4 from Table 4 . We find that, even after controlling for $I V O L$ extracted from longer-dated options, EVOL continues to have incremental predictive power.

Next, instead of controlling for historical volatility measured over the prior four years $(H V O L)$, we use four individual lags of annual stock return volatility. The Akaike Information Criterion (AIC) and the Bayes Information Criterion (BIC) tests indicate modest empirical gains from including more than four years of data. We re-estimate column 4 of Table 4 and find that our results are insensitive to this alternative specification. We also use two common GARCH-class models, GARCH $(1,1)$ and GJR-GARCH $(1,1)$, and find that our inferences are unchanged. We also re-estimate column 5 of Table 4, which includes firm fixed effects. Including firm fixed effects in a dynamic panel data setting with lagged values of the dependent variable introduces Nickell (1981) bias, because the correlation between the lagged values and the individual's average error term is not zero. To address this bias, we re-estimate the column 5, Table 4, model with firm fixed effects using the Arellano and Bond (1991) estimator and find that $E V O L$ also has within-firm predictive power. ${ }^{20}$ The coefficient on EVOL remains positive and statistically significant.

Next, we examine whether the forecasting power of $E V O L$ for stock return volatility relates to forecasting difficulty. To capture the degree of difficulty, we use the magnitude of absolute analyst forecast errors and absolute management forecast errors of earnings. We expect the predictive power of $E V O L$ to be lower when forecasting is harder. Consistent with our expectation, we find that $E V O L$ is less informative for firm-years with higher absolute analyst forecast errors and higher absolute management forecast errors.

Finally, we re-estimate column 4 of Table 4 in a change specification as well as after including lagged $E V O L$ and find consistent results. We also repeat our primary analyses using Fama-Macbeth regressions with industry fixed effects. Again, we find consistent results.

\section{Conclusion}

Accurately forecasting stock return volatility is important but difficult. We study whether the expected volatility $(E V O L)$ that managers disclose in financial reports can forecast stock return volatility and whether its informativeness is affected by earnings management incentives. We conjecture that these forecasts contain managers' private information about strategic decisions and the implications of these decisions for future performance. If this is true, EVOL should have forecasting power for volatility that is incremental to other sources of public information.

\footnotetext{
${ }^{20}$ Proposed solutions for the Nickell (1981) bias, such as the Arellano and Bond (1991) estimator, can still be subject to substantial bias and limitations, because they make strong assumptions about the time-series correlation structure of the dependent variable and use many endogenous instruments (Angrist and Pischke 2008; Roodman 2009; Hausman and Pinkovskiy 2017).
} 
We find that $E V O L$ contains predictive information about near-term and longer-term stock return volatility not captured by implied volatility, historical volatility, firm characteristics, or various fixed effects. $E V O L$ also improves out-of-sample forecast accuracy. Examining the information content of EVOL, we find that $E V O L$ forecasts both earnings volatility and investments and interpret this as evidence that EVOL contains managers' private information about strategic decisions and their implications for future performance. Further, in within-firm analyses, we find that the incremental information content of $E V O L$ is attenuated by incentives to manipulate earnings. Finally, we show that $E V O L$ is not fully incorporated in option prices and is positively associated with volatility straddle returns. Overall, we provide novel evidence that management forecasts of volatility contain private information about firms' underlying uncertainties, and that this information can help to forecast stock return volatility, earnings volatility, and investments.

Acknowledgements We thank Brad Badertscher, Brian Cadman, Maria Correia, Peter Easton, Domenico Giannone, Zhaoyang Gu, Rachel Hayes, Zachary Kaplan, Melissa Martin, Francisco de Asís Martínez-Jerez, Stephen Penman (editor), Marlene Plumlee, Scott Richardson, Matthew Ringgenberg, Suhas Sridharan, Feng Zhang, Ivy Zhang, two anonymous reviewers, and seminar participants at University of Illinois at Chicago, University of Notre Dame, Rutgers University, University of California, Riverside, and University of Utah for helpful comments and suggestions. We are grateful to Ane Tamayo for sharing analyst risk ratings data, and to Mac Gaulin for sharing risk factor disclosure data. We acknowledge excellent research assistance from Arthur Morris.

\section{Appendix}

Appendix 1 Variable Definitions

\begin{tabular}{|c|c|}
\hline Variables & Descriptions \\
\hline \multicolumn{2}{|l|}{ Main Variables: } \\
\hline$E V O L_{t}$ & $\begin{array}{l}\text { Expected stock return volatility over the life of the options granted during the } \\
\text { fiscal year disclosed in the stock compensation expense footnote for fiscal } \\
\text { year-end } t \text { in the firm's } 10-\mathrm{K} \text {. }\end{array}$ \\
\hline$I V O L_{t}$ & $\begin{array}{l}\text { The average implied volatility for at-the-money call options with a 30-day } \\
\text { expiration date during the last month of the fiscal year. The data is from the } \\
\text { standardized option price files (stdopdYYYY) in OptionMetrics, which } \\
\text { contain information on "standardized" (interpolated) options. A standardized } \\
\text { option is only included if there exists enough option price data on a date to } \\
\text { accurately interpolate the required values. }\end{array}$ \\
\hline$H V O L_{t}$ & Historical stock return volatility over the 48 months prior to the fiscal year-end. \\
\hline \multicolumn{2}{|c|}{ Dependent Variables: } \\
\hline Volatility $_{t+1}$ & $\begin{array}{l}\text { One-year lead of Volatility }, \text { which is stock return volatility over the } 12 \text { months } \\
\text { prior to the fiscal year-end } t \text { and is annualized by multiplying with } \sqrt{12} \text {. }\end{array}$ \\
\hline Volatility $_{t+2}$ & Two-year lead of Volatility. \\
\hline Volatility $_{t+3}$ & Three-year lead of Volatility. \\
\hline Volatility $_{t+4}$ & Four-year lead of Volatility. \\
\hline$\sigma(R O A)_{t+2}$ & $\begin{array}{l}\text { Earnings volatility measured as the standard deviation of quarterly ROA over } \\
\text { the next two years (eight quarters). }\end{array}$ \\
\hline Low Growth $t+2$ & $\begin{array}{l}\text { An indicator variable that equals } 1 \text { when the yearly earnings growth from year } \\
t t+1 \text { to } t+2 \text { is in the lowest quintile, } 0 \text { otherwise. }\end{array}$ \\
\hline High Growth Gr $_{2}$ & $\begin{array}{l}\text { An indicator variable that equals } 1 \text { when the yearly earnings growth from year } \\
t t+1 \text { to } t+2 \text { is in the highest quintile, } 0 \text { otherwise. }\end{array}$ \\
\hline
\end{tabular}


Appendix 1 (continued)

\begin{tabular}{ll}
\hline Variables & Descriptions \\
\hline$M \& A_{t+1}$ & An indicator variable that equals 1 if the firm makes an acquisition over the next \\
fiscal year, 0 otherwise. \\
An indicator variable that equals 1 if the firm makes an acquisition over the next \\
two fiscal years, 0 otherwise. \\
Research and development expenditures (Compustat item XRD) over the next \\
fiscal year scaled by total assets at fiscal year-end. \\
Research and development expenditures (Compustat item XRD) over the next \\
two fiscal years scaled by total assets at fiscal year-end. \\
Option straddle return from taking a long position in both an at-the-money \\
(ATM) call and ATM put option of 30-day maturity each month over the \\
11-month period following 10-K filing dates. Following Goyal and Saretto \\
(2009), we identify call and put option pairs with the same strike price \\
maturing within 29 to 31 days that have moneyness between 0.975 and 1.025. \\
We select the first pair with moneyness closest to 1.0. The dollar return for \\
the straddle is calculated as the absolute difference between the price of the \\
underlying stock 30 days after the position is taken and the option strike price \\
(i.e., 30-day stock price - strike price), net of premiums paid for the ATM call \\
and ATM put options, where premiums are measured as the mid-point of \\
quoted bid and ask prices. The percentage return for the straddle is then \\
calculated as the dollar return divided by the initial investment (i.e., the sum \\
of the premiums paid for the ATM call and ATM put options). We use traded \\
options data from OptionMetrics (opprcdYYYY files). \\
Ret Straddle after transaction costs at 50\% of the quoted bid-ask spread.
\end{tabular}

Control and Other Variables:

$\sigma(R O A)_{t}$

Size $e_{t}$

Book-to-price ${ }_{t}$

Earnings-to-price ${ }_{t}$

Loss Indicator

Leverage $_{t}$

$R O A_{t}$

Beta $_{t}$

Momentum

$\sigma(R O A)_{t+1}$

$M \& A_{t}$

$R \& D_{t}$
Earnings volatility measured as the standard deviation of quarterly $R O A$ over the current and past year (eight quarters).

Natural logarithm of market value of equity at fiscal year-end.

The book-to-price ratio computed as book value of common equity at the end of each fiscal year scaled by market value of equity.

Estimated forward earnings yield measured using earnings before extraordinary items (Compustat item IB) for the trailing 12 months scaled by price (market value of equity) at fiscal year-end.

An indicator variable that equals 1 when earnings are negative, 0 otherwise.

Leverage measured using total liabilities scaled by the sum of market value of equity and total liabilities (Compustat item LT).

Return on assets measured as earnings before extraordinary items (Compustat item IB) for the trailing 12 months scaled by total assets.

Firm-specific measure of systematic risk estimated using rolling regressions of firm returns on the returns for the value-weighted market index in CRSP over the prior 36 months (minimum of 24 months required).

Cumulative returns over the prior 12 months, skipping the most recent month (i.e., months -2 to -12 ).

Earnings volatility measured as the standard deviation of quarterly $R O A$ over the next year (four quarters).

An indicator variable that equals 1 if the firm makes an acquisition over the current fiscal year, 0 otherwise.

Research and development expenditures (Compustat item XRD) over the current fiscal year scaled by total assets at previous fiscal year-end. 
Appendix 1 (continued)

\begin{tabular}{|c|c|}
\hline Variables & Descriptions \\
\hline Post $123 R_{t}$ & $\begin{array}{l}\text { An indicator variable that equals } 1 \text { for fiscal years ended after June 2006, which is } \\
\text { the effective date for SFAS 123R (currently known as ASC 718), } 0 \text { otherwise. }\end{array}$ \\
\hline Option Grants $_{t}$ & $\begin{array}{l}\text { Employee stock options granted during the current fiscal year (Compustat item } \\
\text { OPTGR) scaled by common shares outstanding (Compustat item CSHO). }\end{array}$ \\
\hline Small Profit $t_{t}$ & $\begin{array}{l}\text { An indicator variable that equals } 1 \text { if return on assets (ROA) is between } 0 \% \text { and } \\
1 \%, 0 \text { otherwise. }\end{array}$ \\
\hline Small Miss $_{t}$ & $\begin{array}{l}\text { An indicator variable that equals } 1 \text { if reported earnings per share (EPS) are up to } \\
\text { one cent below analyst consensus EPS forecast from } \mathrm{I} / \mathrm{B} / \mathrm{E} / \mathrm{S}, 0 \text { otherwise. }\end{array}$ \\
\hline Small Beat $t_{t}$ & $\begin{array}{l}\text { An indicator variable that equals } 1 \text { if reported EPS are up to one cent above } \\
\text { analyst consensus EPS forecast from } \mathrm{I} / \mathrm{B} / \mathrm{E} / \mathrm{S}, 0 \text { otherwise. }\end{array}$ \\
\hline$G$-Index & $\begin{array}{l}\text { Governance index from Gompers et al. (2003). High values of G-Index indicate } \\
\text { weaker governance. }\end{array}$ \\
\hline$C V(\text { Analyst Estimates })_{t}$ & $\begin{array}{l}\text { Coefficient of variation in analyst forecasts of earnings-per-share for the } \\
\text { one-year-ahead period. }\end{array}$ \\
\hline$\sigma(E / P)_{t}$ & $\begin{array}{l}\text { The standard deviation of earnings-to-price (as defined above) estimated over the } \\
\text { current and past years (eight quarters). }\end{array}$ \\
\hline$\sigma(\Delta B / P)_{t}$ & $\begin{array}{l}\text { The standard deviation of the change in book-to-price }(\mathrm{B} / \mathrm{P}) \text { ratio estimated over } \\
\text { the current and past years (eight quarters), where } \mathrm{B} / \mathrm{P} \text { is as defined above. }\end{array}$ \\
\hline$\sigma\left(R_{N O A} \text { quantile }\right)_{t}$ & $\begin{array}{l}\text { A quantile-based measure of dispersion in forecasted RNOA following } \\
\text { Correia et al. (2018) (see their Appendix III). }\end{array}$ \\
\hline Risk Factors $_{t}$ & $\begin{array}{l}\text { Natural logarithm of the word count (excluding stop words) in the risk factor } \\
\text { disclosure (Item 1A) following Campbell et al. (2014). }\end{array}$ \\
\hline$I V O L_{t}^{\text {Traded }}$ & $\begin{array}{l}\text { The average implied volatility for the traded at-the-money call and put options } \\
\text { used o calculate straddle return (Ret } t_{\text {Straddle }} \text { ). The data is from the traded } \\
\text { option price files (opprcdYYYY) in OptionMetrics. }\end{array}$ \\
\hline$E V O L_{t}-I V O L_{t}^{\text {Traded }}$ & The difference between $E V O L_{t}$ and $I V O L_{t}^{\text {Traded }}$ \\
\hline$H V O L_{t}-I V O L_{t}^{\text {Traded }}$ & The difference between $H V O L_{t}$ and $I V O L_{t}^{\text {Traded }}$. \\
\hline
\end{tabular}

Open Access This article is licensed under a Creative Commons Attribution 4.0 International License, which permits use, sharing, adaptation, distribution and reproduction in any medium or format, as long as you give appropriate credit to the original author(s) and the source, provide a link to the Creative Commons licence, and indicate if changes were made. The images or other third party material in this article are included in the article's Creative Commons licence, unless indicated otherwise in a credit line to the material. If material is not included in the article's Creative Commons licence and your intended use is not permitted by statutory regulation or exceeds the permitted use, you will need to obtain permission directly from the copyright holder. To view a copy of this licence, visit http://creativecommons.org/licenses/by/4.0/.

\section{References}

Aboody, D., Barth, M., \& Kasznik, R. (2006). Do firms understate stock option-based compensation expense disclosed under SFAS 123? Review of Accounting Studies, 11(4), 429-461.

Andersen, T., Bollerslev, T., Diebold, F., \& Labys, P. (2003). Modelling and forecasting realized volatility. Econometrica, 71(2), 579-625.

Andersen, T., Bollerslev, T., \& Meddahi, N. (2005). Correcting the errors: Volatility forecast evaluation using high-frequency data and realized volatilities. Econometrica, 73(1), 279-296. 
Andersen, T., Bollerslev, T., Christoffersen, F., \& Diebold, F. (2006). Volatility and correlation forecasting. In G. Elliott, C. W. J. Granger, \& A. Timmermann (Eds.), Handbook of economic forecasting. Amsterdam: North-Holland.

Angrist, J, D. \& Pischke, J, S.. (2008). Mostly harmless econometrics: An empiricist's companion. New Jersey: Princeton University Press.

Arellano, M., \& Bond, S. (1991). Some tests of specification for panel data: Monte Carlo evidence and an application to employment equations. Review of Economic Studies, 58(2), 277-297.

Bartov, E., Mohanram, P., \& Nissim, D. (2007). Managerial discretion and the economic determinants of the disclosed volatility parameter for valuing ESOs. Review of Accounting Studies, 12(1), 155-179.

Burgstahler, D., \& Dichev, I. (1997). Earnings management to avoid earnings decreases and losses. Journal of Accounting and Economics, 24(1), 99-126.

Cadman, B. D., Carrizosa, R., \& Peng, X. (2020). Compensation disclosures and corporate governance through shareholder voting. Journal of Management Accounting Research, 32(3), 27-48.

Campbell, J. L., Chen, H., Dhaliwal, D. S., Lu, H., \& Steele, L. B. (2014). The information content of mandatory risk factor disclosures in corporate filings. Review of Accounting Studies, 19(1), 396-455.

Carter, M. E., Lynch, L., \& Tuna, İ. (2007). The role of accounting in the design of CEO equity compensation. The Accounting Review, 82(2), 327-357.

Chang, W., Monahan, S., Ouazad, A. \& Vasvari, F. (2020). The higher moments of future earnings. The Accounting Review (forthcoming).

Choudhary, P. (2011). Evidence on differences between recognition and disclosure: A comparison of inputs to estimate fair values of employee stock options. Journal of Accounting and Economics, 51(1-2), 77-94.

Correia, M., Kang, J., \& Richardson, S. (2018). Asset volatility. Review of Accounting Studies, 23(1), $37-94$.

Corsi, F. (2009). A simple approximate long-memory model of realized volatility. Journal of Financial Econometrics, 7(2), 174-196.

Degeorge, F., Patel, J., \& Zeckhauser, R. (1999). Earnings management to exceed thresholds. The Journal of Business, 72(1), 1-33.

Dhaliwal, D., Kaplan, S., Laux, R., \& Weisbrod, E. (2013). The information content of tax expense for firms reporting losses. Journal of Accounting Research, 51(1), 135-164.

Ellahie, A. (2020). Earnings beta. Review of Accounting Studies, (forthcoming).

Ellahie, A., Katz, M. \& Richardson, S. (2020). Risky value. Working paper. University of Utah and London Business School. Available at https://ssrn.com/abstract=2325524.

Fama, E., \& French, K. (1992). The cross-section of expected stock returns. Journal of Finance, 47(2), 427465.

Fama, E., \& French, K. (1995). Size and book-to-market factors in earnings and returns. Journal of Finance, $50,131-155$.

Fama, E., \& Macbeth, J. D. (1973). Risk, return, and equilibrium: Empirical tests. Journal of Political Economy, 81(3), 607-636.

Financial Accounting Standards Board (FASB). (1995). Statement of Financial Accounting Standards No. 123: Accounting for stock-based compensation. Norwalk: CT.

Financial Accounting Standards Board (FASB). (2004). Statement of Financial Accounting Standards No. 123 (revised 2004): Share-based payment. Norwalk: CT.

Gompers, P., Ishii, J., \& Metrick, A. (2003). Corporate governance and equity prices. Quarterly Journal of Economics, 118(1), 107-156.

Goodman, T., Neamtiu, M., \& Zhang, F. (2018). Fundamental analysis and option returns. Journal of Accounting, Auditing and Finance, 33(1), 1-26.

Goyal, A., \& Saretto, A. (2009). Cross-section of option returns and volatility. Journal of Financial Economics, 94(2), 310-326.

Hausman, J, A. \& Pinkovskiy, M.. (2017). Estimating dynamic panel models: Backing out the Nickell bias. Federal Reserve Bank of New York Staff Report no. 824. Available at https://ssrn.com/abstract=3066691.

Hayes, R., Lemmon, M., \& Qiu, M. (2012). Stock options and managerial incentives for risk taking: Evidence from FAS123R. Journal of Financial Economics, 105(1), 174-190.

Hemmer, T., Matsunaga, S., \& Shevlin, T. (1996). The influence of risk diversification on the early exercise of employee stock options by executive officers. Journal of Accounting and Economics, 21(1), 45-68.

Hodder, L., Mayew, W., McAnally, M., \& Weaver, C. (2006). Employee stock option fair-value estimates: Do managerial discretion and incentives explain accuracy? Contemporary Accounting Research, 23(4), 933975.

Huddart, S., \& Lang, M. (1996). Employee stock option exercises an empirical analysis. Journal of Accounting and Economics, 21(1), 5-43. 
Johnston, D. (2006). Managing stock option expense: The manipulation of option-pricing model assumptions. Contemporary Accounting Research, 23(2), 396-425.

Konstantinidi, T., \& Pope, P. (2016). Forecasting risk in earnings. Contemporary Accounting Research, 33(2), 487-525.

Kothari, S. P. (2001). Capital markets research in accounting. Journal of Accounting and Economics, 31(1-3), $105-231$.

Kravet, T., \& Muslu, V. (2013). Textual risk disclosures and investors' risk perceptions. Review of Accounting Studies, 18(4), 1088-1122.

Lewellen, J. (2015). The cross-section of expected stock returns. Critical Finance Review, 4, 1-44.

Li, N., Richardson, S., \& Tuna, İ. (2014). Macro to micro: Country exposures, firm fundamentals, and stock returns. Journal of Accounting and Economics, 58(1), 1-20.

Lui, D., Markov, S., \& Tamayo, A. (2007). What makes a stock risky? Evidence from sell-side analysts' risk ratings. Journal of Accounting Research, 45(3), 629-665.

Lui, D., Markov, S., \& Tamayo, A. (2012). Equity analysts and the market's assessment of risk. Journal of Accounting Research, 50(5), 1287-1317.

Lyle, M., Callen, J., \& Elliott, R. (2013). Dynamic risk, accounting-based valuation and firm fundamentals. Review of Accounting Studies, 18, 899-929.

McAnally, M. L., Srivastava, A., \& Weaver, C. D. (2008). Executive stock options, missed earnings targets, and earnings management. The Accounting Review, 83(1), 185-216.

Minton, B., Schrand, C., \& Walther, B. (2002). The role of volatility in forecasting. Review of Accounting Studies, 7(2-3), 195-215.

Nickell, S. (1981). Biases in dynamic models with fixed effects. Econometrica, 49(6), 1417-1426.

Ou, J., \& Penman, S. (1989a). Financial statement analysis and the prediction of stock returns. Journal of Accounting and Economics, 11(4), 295-329.

Ou, J., \& Penman, S. (1989b). Accounting measurement, price-earnings ratios, and the information content of security prices. Journal of Accounting Research, 27(supplement), 111-152.

Penman, S., Reggiani, F., Richardson, S., \& Tuna, I. (2018). A framework for identifying accounting characteristics for asset pricing models, with an evaluation of book-to-price. European Financial Management, 24(4), 488-520.

Poon, S., \& Granger, C. (2003). Forecasting volatility in financial markets: A review. Journal of Economic Literature, 51(2), 478-539.

Poon, S., \& Granger, C. (2005). Practical issues in forecasting volatility. Financial Analyst Journal, 61(1), 4556.

Roodman, D. (2009). A note on the theme of too many instruments. Oxford Bulletin of Economics and Statistics, 71(1), 135-158.

Securities and Exchange Commission (SEC) (2005). Topic 14: Share-based payment. Staff Accounting Bulletin. Available at: http://www.sec.gov/interps/account/sabcodet14.htm.

Sridharan, S. (2015). Volatility forecasting using financial statement information. The Accounting Review, 90(5), 2079-2106.

Publisher's note Springer Nature remains neutral with regard to jurisdictional claims in published maps and institutional affiliations. 